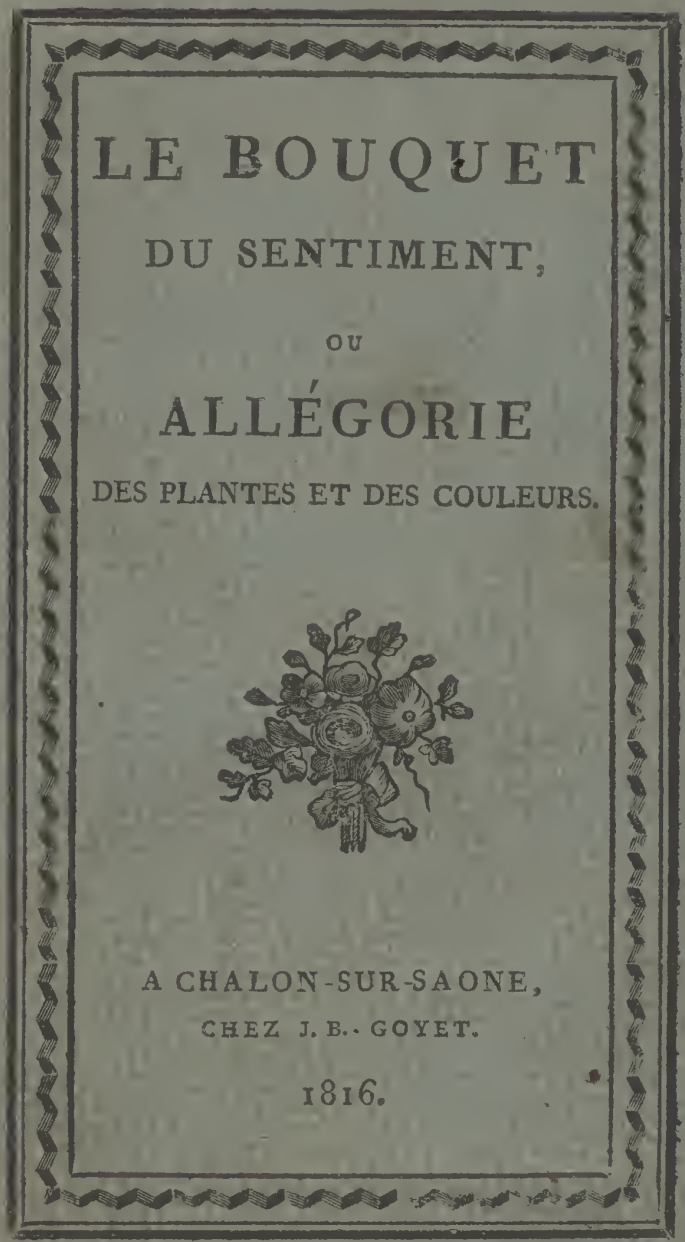




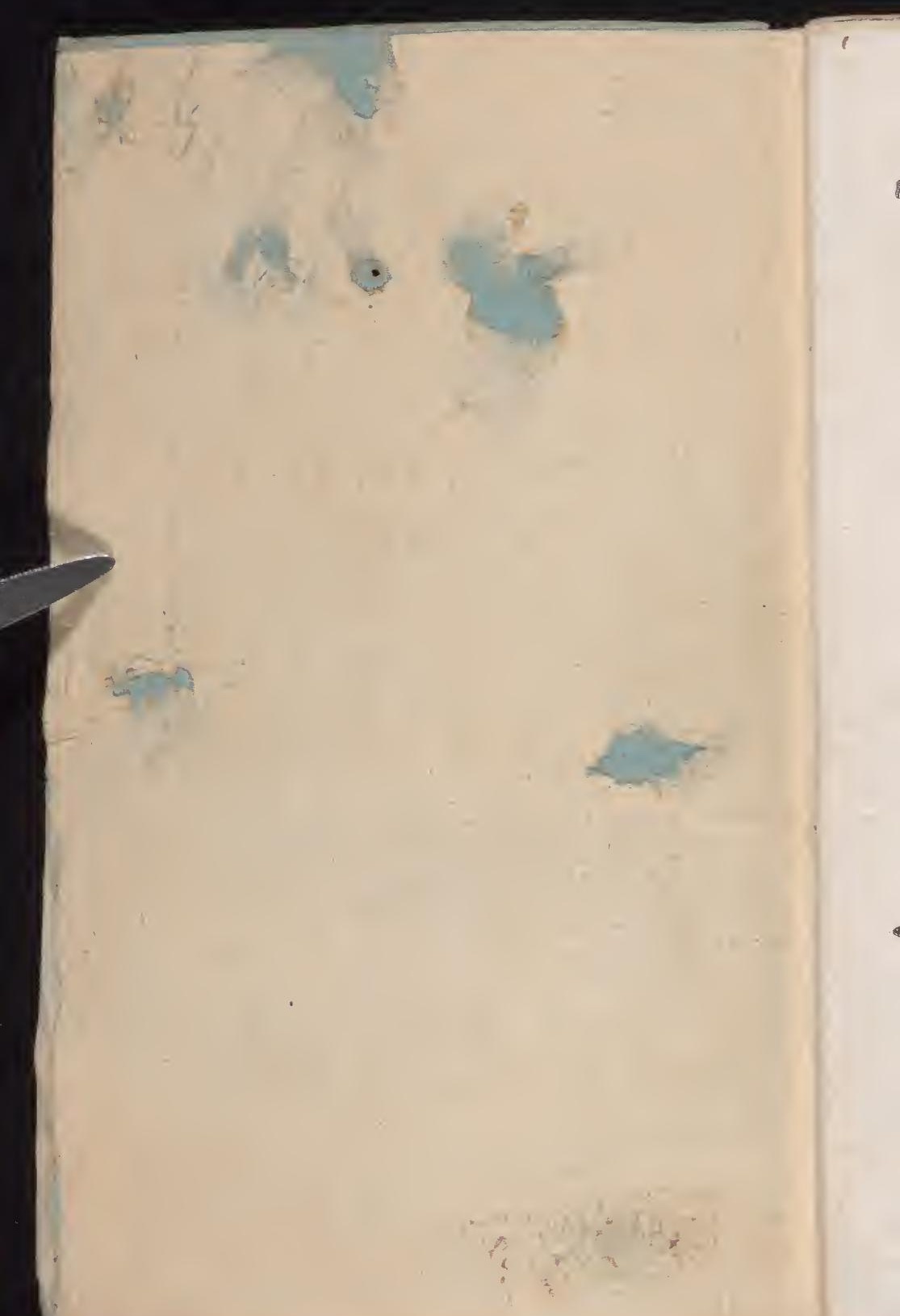



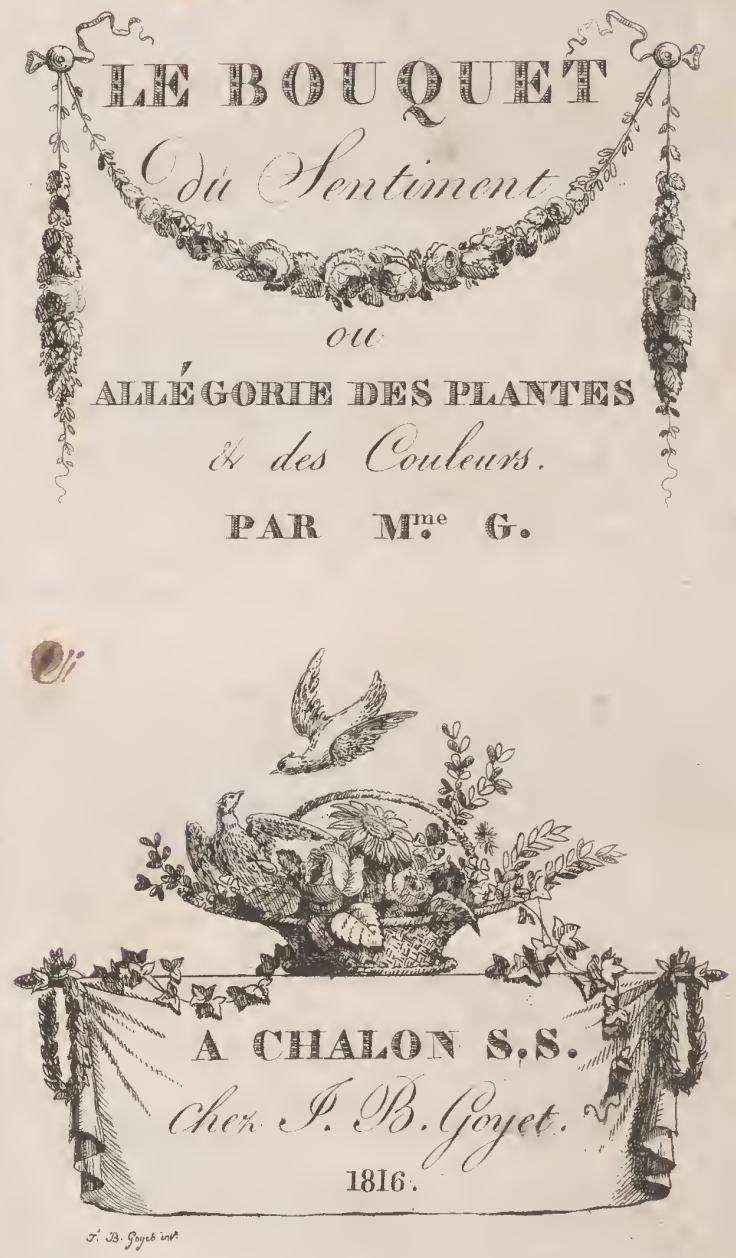
hicoog Botanic Gatd.
Library 


\section{DISCOURS PRÉLIMINAIRE:}

Lorsque la nature, après ur long deuil, reprend ses habits de fêtes, les fleurs s'empressent de former sa brillante parure; elles viennent, pour nous consoler de leur absence, embaumer l'air d'un parfum délicieux, et à l'envi l'une de l'autre étaler à nos regards les plus riches couleurs. Papillons, autres fleurs habitantes des airs, đéjà vous déployez vos ailes veloutées, et rivaux du zéphir vous leur destinez vos caresses: mais la jeune beauté guette la rose qu'elle cultive; elle vient d'éclore, et déjà elle relève la blancheur de soin sein. Et toi, joli muguet, ornement de nos vallons, Flore t'a fait naître pour parec l'humble corset de la modeste bergère! Fleurs charmantes, quel plaisir ne procurent pas les soins qu'on vous donne! comme l'on aime à suivre toutes les périodes de votre existence, vos amours, vos chastes hymens! Il me semble voir l'étonnement de la jeune et timide vierge, qui, pour la première fois, portes sa chaste main sur la sensitive aussi pudique qu'elle. 
Que mon ame est émue, lorsque dans un jour consacré à la piété je vois mille festons de fleurs se dessiner agréablement sur une draperie blanche, sy $\mathrm{m}$ bole de la pureté, et qu'un jeune enfant, la tète couronnée de bluets, offre à l'Eternel l'encens de l'innocence!

Fleurs aimables! Heurẹux celui qqui sait préluder sur la lyre des chants en votre honneur!

L'usage des fleurs était si général chez les anciens, qu'ils s'en couronnaient dans les banquets, qu'ils en mettaient des festons autour de leurs cous. On jetait des fleurs sur le passage des personnes qu'on voulait hororer; les amans ornaient de guirlandes les maisons de leurs maîtresses, et celui qui portait une bonne nouvelle était couronné de fleurs. Les femmes employaient des couronnes de fleurs pour faire connaître leurs sentimens; la manière de les disposer, leur couleur et leur odeur même caractérisaient leur signification. On couvrait de fleurs les corps qu'on. portait au bûcher, et l'on en parait les tombeaux, usage qui se pratiquait tous les ans au jour anniver. saire des funérailles.

Les premiers chrétiens qui regardaient les fleura 
comme symbole des dons du Saint-Esprit et des délices du paradis, dans les jours de fêtes en ornaient l'intérieur des églises.

Dans l'Inde les sentimens délicats de l'amour; les sentimens purs de l'amitié s'expriment par des fleurs; ce langage n'est pas parvenu jusqu'à nous. M. Hammer (I) nous a transmis des allégories do fleurs et de fruits, tirées des harems, et qui se réduisent a faire rimer le dernier mot de la phrase avec le nom de la fleur: le bon goût ne saurait en être satisfait.

Depuis quelques années le désir d'employer le langage desfleurs s'est tellement manifesté parmi nous, que beaucoup de personnes n'en offrent presque plus, sans chercher à exprimer dans leurs bouquets le symbole de leurs sentimens. On s'est empressé de se communiquer des manuscrits d'allégories de fleurs dont quelques significations étaient assez heureuses, mais dont la plus grande partie paraissait choisie par le caprice: je me proposai donc de faire à loisir uı

(1) Annales des Voyages de la Géographie et de l'Histoire, publicés par M. IIalle-Brun. 
recueil dont l'allégorie de chaque plante serait priso d'après ses propriétés naturelles, son historique où son rapport avec la mythologie, quelquefois d'aprè's sa beauté et sa couleur.

Dans cet intervalle parut l'abécédaire de Flore; qui parle de l'allégorie des plantes et en donne quelques significations, mais dont le but principal est d'enseigner la manière d'écrire en se servant d'une fleur pour une lettre ou une syllabe, moyen qu'on ne peut guère employer qu'en dessinant.

Ce petit ouvrage que je nommerai le Bouquet da Sentiment, contient l'allégorie de près de trois cents plantes par lesquelles j'ai exprimé toutes les sensations heureuses ou malheureuses; afin de le rendre plus intéressant, et sur-tout pour justifier le symbole de chaque fleur, car je n'ai pas l'intention d'instruire personne, $j$ 'ai indiqué l'époque de sa floraison, les lieux où on la trouve, ses propriétés naturelles, et son historique. Le nouveau Dictionnaire d'Histoire naturelle appliquée aux arts, etc. par une société de naturalistes et d'agriculteurs; les Plantes de La France, par M. Jaume-Saint-Hilaire, et l'Encyclopédie pour l'antiquité, sont les sources où j’ai puisś. 
Un auteur (1) a dit que, "prendre le souci pour le symbole des soucis moraux, et la pensée pour le symbole des pensées intellectuelles, ce serait faire un jeu de mots d'autant plus ridicule, que ces fleurs ont des noms tout-à-fait différens dans toutes les autres langues; " quoique l'opinion d'un auteur de ce mérite puisse bien faire autorité, je n'ai pu me décider à abandonner pour symbole de la pensée cette jolie fleur qui en portele nom. Enfermée dans un livre, elle conserve parfaitement ses couleurs; lorsqu'elle a été offerte par l'amitié, on se plaît à la revoir, et sa conservation rappelle et l'ami qui l'a donnée et le sentiment qui l'a fait offrir; c'est de-lit que la pensée tire son nom. C'est aussi pour cette raison qu'en Allemagne la jolie petite fleur nyosotis y reçoit un nom qui signifie ne m'oubliez pas,

Quant au souci, je l'aurais volontiers abanciomé si j'eusse trouvé une autre fleur qui exprimât d'une manière plus positive l'inquiétude, les soupçons, la jalousie; signification qu'on peut cependant lui donner sous le rapport mythologique.

(1) Tradame de Genlis, Journal des Dimancỉes, 
Le nom de souci vient de solsequium, qui re. cherche le soleil, parce que ses fleurs se ferment lorsque le soleil se couche et s'ouvrent quand il se lève, ce qui a fait dire à qquelqques poëtes que cette fleur avait été jadis une jeune fille aimée d'Apollon, qui était morte de jalousie.

Rapin, dans son Poëme des Jardins, dit, en parlant du souci (1): «Amante du soleil, votre fleur, en considérant l'astre qu'elle adore, a reçu de lui la couleur dont elle éblouit nos regards. »

J'ai conservé avec soin les symboles consacrés par l'antiquité et parl'usage ; $j$ 'ai de même conservé ceux nouvellement donnés à quelques fleurs, lorsqu'ils se sont trouvés d'accord avec la loi que je me suis imposée en faisant cet ouvrage.

$J^{\prime}$ ai donné quelques exemples de bouquets à offrir, mais on sentira parfaitement ce que je n'ai fait qqu'esquisser, et qu'à défaut de fleurs on peut en présenter les feuilles.

C'est pour les personnes qui. dessirent, mais qui

(1) Noles sur les Idylles morales, par MT. E. Cons. tani Dubos. 
ne se livrant pas entièrement à l'art, et qui ne lui donnant que des instans de loisir ne peuvent en faire une étude sérieuse, que j'ai ajouté le symbole des arbres; elles augmenteront leurs jouissances en composant des sujets allégoriques; elles y trouveront aussi la manière de grouper les fleurs. Le GrandLivre des Peintres par Gérard de Lairesse m'a fourni les matériaux pour cet artícle, quî̀ sera de même utile pour disposer avec grâce les fleurs qui doivent orner un appartement.

J'ai pensé que l'allégorie des couleurs devait trouver ici sa place, afin que le ruban avec lequel on attacherait un bouquet devînt aussi symbolique.

I a nomenclature des différens sentimens suivis de la fleur qui en est le symbole, termine cet ouvrage que j'ai orné de petites estampes qui viendront à rappui des exemples que j'ai donnés.

Si des enfans soumis ont trouvé dans l'allégorie de mes fleurs un moyen de plus d'exprimer aux auteurs de leurs jours un amour respectueux; si les sentimens délicats de l'amour y ont trouvé des expressions; si l'amitié y a puisé de nouvelles jouissances; si mon langage rend à l'hymex un beau jour qu'un 
léger nuage aurait obscurci; si enfin celui qui reçuz un bienfait l'emploie pour témoigner sa reconnaissance, $j$ 'aurai atteint mon but.

whomenamomans 


\title{
LE BOUQUET
}

DU SENTIMENT,

\author{
ov \\ ALLÉGORIE
}

DES PLANTES ET DES COULEURS. (1)

nomanasomas

Absinthe citronnelle. Préservatif; j'éloignerai de vous les méchans.

On cultive cette absinthe dans les jardins et sur les fenêtres, sous le nom de citronnelle, de garde-robe et d'aurorre des jarclins; son odeur qui approche de celle du camphre et du citron chasse les insectes de la laine.

A BSINTHE vulgaire. Toul m'abrenpez d"amertume.

L'absinthe vulgaire croît dans toute l'Europe tempérée autour des villages, dans les décombres, et sur la lisière des bois; elle est amère et odorante; son nom qui vient du grec signifie sans douceur. 
ACACIA. Sagesse, mystère.

Depuis long-temps l'acacia est naturalisé en France: ses jolies fleurs dont l'odeur ressemble à celle de la fleur d'orange se montrent au printempe. Les anciens avaient consacré cet arbre à la sagesse; il sert d'emblême à la franc-maçonnerie.

ACACIE purlique ou sensitive. Extrême sensibilité, pudeur.

La sensitive tient son nom des phénomènes surprenans qu'elle présente; on sait que ses feuilles se replient sur elles-mếmes si on les touche; elle montre aussi de la sensibilité à l'impression du chaud, du froid, de l'orage, et des odeurs fortes. Les Grecs lui avaient donné le nom akakia qui signifie innọcence; Linnée lui donna depuis celui de mimosa, du grec mimos, dérive̊ du verbe mimeomai, faire des gastes.

ACanthe branc-ursine. Amours des beculu-arts.

L'acanthe qui croît en Asie, en Afrique et dans les parties méridionales de l'Europe, se trouve clans les terrains sablonneux et humides.

Une jeune fille de Corinthe étant morte peu de jours avant son mariage, sa nourrice plaça près de son tombeau un panier contenant quelques obiets qu'elle avait aimés, et le couvrit d'une tuile; il se trouva par hasard un pied d'acanthe dont les larges 
feuilles enveloppèrent le panier, et se recourbèrent arrêtées par la tuile: Callimaque, célèbre architecte, ayant apperçu cette décoration, en forma le chapiteau de la colonne corinthienne à qui cette plante doit sa célébrité.

ACHILLÉE mille-feuille. Guérison, guérissez-moi.

L'achillée se trouve dans les terrains incultes et sur le bord des chemins; son norn lui fut donné en mémoire d'Achille, disciple du centaure Chiron, qui s'en servit pour guérir les blessures de Téléphe; elle cicatrise toutes celles faites par le fer.

AConit. Vous me donnez la mort.

Les aconits sont de belles plantes, mais qui cachent un poison dangereux, ce qui a fait dire aux poëtes qqu'ils naquirent de l'écume de Cerbère; ils croissent principalement daos les pays montagneux de l'Europe, et fleurissent en été. Les Germains et les $G$ aulois trempaient leurs flèches dans le suc des aconits pour rendre leurs blessures mortelles.

" On rapporte qu'un jeune homme, habitant du « Mont-Pilate en Suisse, prit des fleurs dans sa main " et descendit.la montagne pour aller à une danse; * arrivè à la salle clu bal champêtre, il sentit sa - main s'engourdir, jeta les fleurs, et dansa quel" ques heures avec une jeune fille. Le poison se cum* muniqua par le simple attouchement, et tous lse 
" deux moururent dans la même soirée." Plantes de la France par M. Jaume-Saint-Hilaire.

ADONIDE d'été. Souvenir tendre et douloureux, sous venir ineffaçable.

L'adonide est une jolie fleur qui vient dans nos blés et paraît vers la fin de l'été; on la cultive dans nos jardins où elle se fait remarquer par la découpure de ses feuilles, et sur-tout par le rouge vif de ses pétales; les poëtes ont dit qu'elle fut teinte du sang d'Adonis, d'où lui vient son nom.

ADOX a musqué. Faiblesse.

L'adoxa habite la France et fleurit en avril et mai; cette plante peu remarquable a une légère odeur de musc. Son nom grec signifie sans gloire, sans éclat.

Agneau chaste. Voyez Gatilier commun.

AlCÉE. Toyez Rose tremière.

Alizier. Accord, soyons d'accord.

Trois espèces d'alizier croissent en Europe; deux sont de grands arbres à fruits, dont le bois qui a une odeur agréable est employé dans les arts, et sert entr'autres choses à faire des flutes et des fifres.

Alysse des rochers, vulgairement la CORbeille d'or. Calme, tranquilllité.

L'alysse des rochers crô̂t dans les terrains mon- 
tueus et arides, et fleurit dans les mois d'avril et de mai; son nom générique, qui vient du grec, signifie qui ôle la rage, parce que les anciens lui attribuaient cette propriété: on s'en sert même encore contre cette maladie.

Ama NDiER commun. Douceur inallérable.

L'amandier commun fleurit aussitôt après les gelées, ses fruits même amers donnent ume huile trèsdouce.

AMANDIER satiné. Tmprudence.

Celui-ci fleurit en février et mars, et croît en France comme l'amandier commun; lorsque ses jolies fleurs paraissent avant la fin des frimas, elles souffrent beaucoup de la gelée.

\section{Amaranthe. Constance.}

C'est ordinairement en automne que fleurissent les amaranthes, et mêrne pendant tout l'hiver sur la cheminée lorsqu'on a eu soin de couper leurs tiges en été. Le nom de cette fleur est composé de deux mots grecs qui signifient qui ne se flétrit point. L'amaranthe d'or est le prix que l'on décerne à une ode c̉ans les jeux floraux à Toulouse.

* Je t'aperçois, belle et noble amaranthe!

« Tu viens m'offrir, pour calmer mes douleurs,

* De ton velours la richesse éclatante; 
* Ainsi la main de l'amitié constante;

«Quand tout nous fuit, vient essuyer nos pleurs.

* Ton doux aspect, de ma lyre plaintive

"A ranimé les accorcls languissans;

« Dernier tribut de Flore fugitive,

* Elle nous lègue, avec sa fleur tardive;

« Le souvenir de ses premiers présens.

* Tel un ami qu'entraîne un long voyage,

* De loin encor tournant les yeux vers nous,

* De ses regrets nous offre un dernier gage;

« Et, de sa main, tendre et muet langage,

« Nous dit: adieu; mon cœur reste avec vous. $\%$

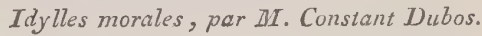

AMARYllis, Toute belle.

A maryllisvient d'un motgrec amaryssô, qui signifie briller. La beauté, la grandeur, la couleur et l'odeur suave de ses fleurs renclent cette plante des plus intéressantes: toutes les espèces sont très-belles; une d'elles est nommée la belle dame des Italiens.

\section{AMbroiste. Immorlalité.}

On cultive fréquemment l'ambroisie dans les jardins de Paris, à raison de sa bonne odeur; cette plante fut très-estimée des anciens. Les Grocs croyaient que ceux qui en mangeaient devenaieat immortels. 
AMOUReTte. Voyez BRIZE tremblante.

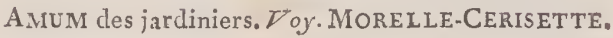

Ananas. Vous réunissez toul.

L'ananas à couronne réunit en lui le goût et le parfum de tous nos meilleurs fruits; on. n'en connaît point de plus excellent : sa culture a été introduite depuis long-temps en Europe.

Ancor.IE. Folie.

L'ancolie est très-commurre dans nos jardins; ses touffes de fleurs violettes qui paraissent en juin et juillet ressemblent assez aux grelots de Momus.

ANEMONE. Innocente victime de la jalcusie.

Les mythologistes racontent que Mars, jaloux. d'Adonis, le fit tuer à la chasse par un sanglier; Vénus le changea en anémone. Cotte fleur qui s'épanouit dans les mois de mars, avril et mai, est trèsrépandue dans nos jardins.

Aneth. Force.

Les trois espéces d'aneth qui sont propres aux parties méridionales de l'Europe, répandent une odeur des plus suaves; c'est sans doute pour cette raison que les Romains en tressaient des couronnes dont ils se paraient dans les festins. Les gladiateurs en mêlaient dans leur nourriture, parce que cette 
plante avait la réputation d'augmenter considéráblement les forces du corps.

Angélique. Satuvez-moi.

L'angélique est une plante intéressante sous tous les rapports; on l'emploie beaucoup en médecine, sur-tout contre la peste. Elle est propre aux pays humides du nord de l'Europe, mais elle croît également dans les terrains secs et exposés au soleil du midi.

ARrête-Equf. Toyez Bugrane.

ARum. Toyez Gouet.

ASPHODELL. MIes regrels vous suivent au tombeat.

Trois espèces d'asphodèle peuvent orner nos jarlins; une d'elles que l'on nomme bâton de Jacob, a des tiges terminées par de beaux épis de fleurs jaunes. Les anciens plaçaient cette plante autour des tombeaux.

Aster ou Reine-MARguerite. Eligance.

Nous devons à la Chine l'aster ou reine-marguerite, "Tès-beile plante, qui fait en automne l'ornement cle nos parterres par la variété de ses couleurs et l'élégance de ses fleurs.

ASTER à grande fleur. Arrière-pensée.

L'aster à grande fleur est recherchée pour l'agré- 
ment des parterres, parce qu'on la voit paraître à une époque où les autres fleurs commencent à être rares.

Al bÉPINE. Doux espoir.

Avec l'aubépine, $\mathrm{j}$ (li arbrisseau très-épineux, on fait d'excellentes clòtures; ses fleurs d'une odeur agréable nous annoncent le retour du printemps. Les Romains prétendaient que l'aubćpine avait la propriété d'écarter les maléfices; et pour cette raison ils en portaient des torches dans les mariages, et en attachaient les branches aux fenêtres des enfans nouveau-nés.

Baguenaudier arborescent. Générosité.

Le baguenaulier est un joli arbrisseau qui fleurit au printemps, et au mois d'août, époque on il se trouve souvent chargé de fleurs et de fruits en même temps; il fournit aux abeilies une abondante récolte.

\section{Batsamine. Impatience.}

La balıamine est très-répandue dans nos jardins dont elle fait l'ornement depuis le mois de juillet jusqu'au mois d'octobre; à l'époque de la maturité de ses graines, les capsules qui les renferment les lancent au loin en se contractant.

\section{BARDANE. Importunité.}

La bardane qui fleurit en août, crốt en Europe 
dans toutes les bonnes terres, autour des villages, où ses têtes s'attachent aux vêtemens; elle s'em. pare aisément des terrains qui lui conviennent, et il est quelquefois difficile de l'extirper.

\section{BASILIC. Tous me rendez le courage.}

L'odzur suave du basilic le fait rechercher de tout le monde; il plaît beaucoup aux abeilles. Ses feuilles dont on tire une huile essentielle servent aussi en infusion à ranimer les forces vitales.

BAUME des jardins. Voyez MENTHE.

BEI.LE-DE-JoUR. Voyez LISERON tricolore.

Be lle-de-Nuit. Voyez Nictage,

BÉTOINE. Surprise, réveil.

C'est dans les lieux secs et ombragès de l'Europe que l'on trouve la bètoine qui fleurit en juillet et août; cette plante répand, lorsqu'il fait chaud, des émanations qui agissent fortement sur les personnes nerveuses; elle est employée dans les maladies de la tête, l'engourdissement des membres, etc.

\section{BLuet des blés. Vous m'éclairez.}

Tout le monde connaît le bluet des blés; depuis qu'on le cultive dans les jarlins, il y en a a fleurs roses, blanches, purpurines, couleur le chair et panachées; on le croyait bon pour les maladies des 
yetrx, ce qqui lui avait fait donner le surnom de casse-lunettes.

BoIs-Gentil. Voyez LaURÉole.

Bouillon-Blanc. Voyez Moléne.

Boule-de-Neige. Voyez VIORNe.

Bovquet parfait. Voyez ErLlet.

BOURRACHE. Energie; vous m'inspirez.

La bourrache naturalisée en Europe fleurit pendant presque toute la belle saison; ses propriétés médicinales ont une grande réputation. On dit que son nom vient des mots latins cor ago, qui signifient jexcile le cour , je ranime.

Bouton d'or. Voyez RenonCule âcre.

Rranc-Ursine. Voyez A CANTte.

Brize tremblante ou AmouretTe. Galanterie, gaieté, frivolité.

La brize tremblante est vivace, propre à l'Europe, et se trouve dans les prés secs et les montagnes privées de bois: les bergers appellent cette plante a mourette à raison de l'agréable aspect qu'elle présente.

BRUYĖRE commune. Solitude; $j$ e cherche la solitude.

C'est dans les terrains incultes et arides, lans les landes sablonneuses, que se trouve la bruyère 
commune; cette plante comprend un très-grand nombre d'espèces diffèrentes, qui ne croissent que dans une nature de terre qui leur est propre.

Bugrane, vulgairement ARRÊTE-BeEuf. Entraves.

Les racines longues et tenaces de la bugrane résistent souvent aux efforts du laboureur, ce quilui a fait donner le nom vulgaire d'arrête-bœuf; elle se trouve dans les champs incultes et le long des chemins, et fleurit depuis le mois de juin jusqu'en octobre.

BuIs. Solidité, durée, stoicisme.

Le buis croît dans cles terrains froids et stériles oł. peu d'autres arbres réussissent; il se plaît à l'ombre, supporte le froid et le chaud, dure fort long-temps, et n'exige presque aucun soin; il fleurit en avril. Cet arbre fut mis chez les anciens sous la protection de. Cybèle.

BuTOME à ombelle, vulgairement JONC fleuri. Grâce; pous êtes remplue de gráces.

Les bords des rivières, les marais dont l'eau n'est. pas croupissante, sont souvent embellis par l'élégante fleur connue sous le nom vulgaire de jonc fleuri, qui étale sa parure dans le fort de l'été.

Cactier raquette. Je brále.

Le nom de cactier vient du verbe grec kaîo, je 
brôle, parce que la piqûre de ses épines cause cles clouleurs brûlantes. Il y en a un grand nombre d'espèces en Amérique, mais on en cultive quelques-unes dans nos jardins.

Camara piquant. Rigueurs.

Le camara est un arbrisseau épineux qui nous vient d'Amérique. On le cultive dans nos jardins.

Cameline cultivée. Doux liens.

On trouve ordinairement la cameline dans les orges, les seigles et les avoines, les tiges de cette piante se filent, et la graine sert a faire de l'huile.

Camomilne romaine. Je me rendrai digne de vos soins.

La camomille est une plante très-intéressante tant par sa bonne odeur que par ses vertus mélicinales; on la trouve dans les pâturages secs, en Italie, en Espagne et en France; elle fleurit dans les mois de juin, juillet et août.

Campanule, rulgairement Miroir de Vézus. Flatterie.

C'est dans nos champs, parmi nos blés que vient ordinairement la iolie plante appelée vulgairement miroir de Vénus; ses fleurs qui paraissent en août se ferment au soleil couchant. 


\section{Capirine. Feu d"amour.}

Les fleurs de la capucine se succèdent dans notre pays pendant toute la belle saison, et même quelquefois jusqu'a l'entrée de l'hiver. Dans les soirées cles jours chauds d'été, il sort de la grande capucine des étincelles électriques.

\section{CÉDRE. Tous êtes digne de t'immortalilé.}

La rareté, la beauté et l'incorruptibilité du cèdre ont rendu cet arbre célèbre; il a le port le plus noble et le plus majestueux, et vit plusieurs siècles. Les anciens l'ont pris pour emblême de l'éternité.

Centaurée musquée, ou Fleur du GrandSeigneur. Vous inspirez la confance.

On cultive la centaurée musquée, plante orioginaire de Turquie, non-seulement à cause de son parfum, mais pour sa beauté. Son port quoique simple, est élégant. Le rom centaurée vient, disent les poëtes, de ce qư'elle guérit le centaure Chiron d'une blessure qu'il s'était faite au- pied en maniant les armes d'Hercule.

\section{Cerisier. Indépendance.}

Le cerisier a conservé un principe sauvage ; il veut pousser à sa fantaisie. Si la serpette du jardinier cherche à le contraindre, il dépérit et meurt promptement. Originaire du royaume de Pont, il fut apporté en Europe par Lucullus. 
CHARME. Ornement, embellissement.

On emploie le charme particulièrement à former des rideaux de verdure, des portiques, des colonnades, et toutes les décorations qui charment agréablement la vue dans les grands jardins.

Chataignier. Connaissez-moi mieux, rendez-moi justice.

Le châtaignier qui réunit toutes les qualités est un des beaux arbres indigènes à la France; il est remarquable par sa hauteur, sa beauté et son port majestueux. Il serait à désirer qu'on le multipliat davantage.

CHÉLIDOINE. Soins maternels.

La grande chélidoine connue sous le nom d'éclaire se trouve dans les lieux humides et ombragés; ce nom lui a été donné parce que l'on prétendait autrefois que l'hirondelle s'en servait pour rendre la vue à ses petits aveuglés; elle fleurit pendant toute la belle saison.

CHÊNE. Force morale, protection, récompense.

Le plus bel arbreindigène à l'Europe est le chêne; il fut autrefois consacré à Jupiter, à Rhée et au dieu Sylvain. Objet de vénération pour les peuples, e'était aussi sous son ombrage que les druides chantaient des hymnes sacrées. Chez les Grecs et les 
Romains une couronne de chêne était la récompense des vertus civiques.

Cheveux de Vénus. Voy. Nigelle de Damas.

Chevre-Feuille. Tiens d'amour.

Le chevre-feuille des jardins est le plus commun; et cependant le plus recherché; on le voit grimper autour des arbres qqui l'avoisinent, et s'y entrelacer d'une manière agréable; ses jolies guirlandes flattent également la vue et l'odorat. On a donné à une espèce de chevre-feuille le nom de periclymenes; ce mot qui vient du verbe grec perikleisô, siguifie jen. zoure de tous côtés.

Chicoréz sauvage. Amertume.

La chicorée sauvage se trouvę communément sur le bord des champs et des chemins; ses fleurs qui paraissent en juillet et août sont grandes et d'un keau bleu. Toute la plante renferme un suc trèsamer,

Chiendent. Persévérance.

Le chiendent est une plante printanière qui multiplie tellement, qu'il est difficile de la détruire; elle était consacrée au dieu Mars. La couronne obsidionale que l'on offrait chez les Romains au guerrier qui avait soutenu ou fait lever le siege d'une ville, était faite de chiendent. 
ChrisanthêME des prés, ou REINE-MARGUERITE. M'aimez-pous.

On trouve abondamment la reine-marguerite dans les prairies et le long des chemins; elle fleurit en été. Il n'est personne qui n'ait remarqué cette plante, et qui dans sa jeunesse n'ait joué avec sa fleur en cherchant à connaître le degré d'affection de l'amant ou de l'amie.

" Souvent la pastourelle,

" Loin de son jeune amant,

" Se dit: m'est-il fidèle ?

* Reviendra-t-il constant?....

" Tremblante elle te cueille;

"Sous son doigt incertain

« L'oracle qui s'effeuille

"Révèle son destin."

$$
\begin{gathered}
\text { Les Fleurs, Idylles morales, } \\
\text { par M. E. Constant Dubos. }
\end{gathered}
$$

Cigue. Trahison.

$\mathrm{La}$ ciguë a beaucoup de ressemblance avecle persil et le cerfeuil sauvage; son odeur est fétide et narcotique. Certe plante dont les fleurs paraissent en juin et juillet a été regardée de tout temps comme un poison.

Circée ou Herbe aux magiciennes. Vous m'enchantez.

La circée croît dans les bois et les lieux couverts 
de l'Amérique et de l'Europe; on l'employait aux enchantemens chez les anciens.

\section{Ciste. Jalousie.}

Le ciste a des étamines si irritables, qu'on le voit s'agiter sans causes apparentes; il est propre aux parties méridionales de l'Europe, et fleurit en juin et juillet.

Citronnelle, Voyez Absinthe.

Clandestine ou Herbe cachée. Amour caché.

La clandestine, plante parasite dont il n'y a que les fleurs d'apparentes, se trouve difficilement, étant presque toujours cachée sous la mousse, au piell des grands arbres; elle habite les lieux ombragés, froids et humicles de la France, et ne fleurit que vers la fin du printemps.

\section{CiématTtTe bleue. Liens.}

On fait des liens et cle jolis paniers avec la clématite bleue, plante sarmenteuse qui fleurit dans les mois de juin, juillet, août et septembre; elle tapisse agréablement les murailles, et peut parcette raison contribuer à l'ornement des jardins. On l'appelle vignette dans quelques pays.

Cocrette des prés. Entêtement.

La cocrette croît en abondance dans nos prés, 
q̧u'elle détériore; il faut, pour la détruire, l'arracher exactement deux ou trois années de suite. Elle fleurit en juin et juillet.

\section{Coquelicot. Voyez Pavot.}

CoQuelourde. Vous êtes sans prétention.

Originaire de Suisse et d'Italie, la coquelourde est une assez jolie plante, dont les fleurs qui ressemblent à un petit œillèt paraissent en grand nombre pendant tout l'été; son nom agrostemma, composé de deux mots grecs, agros et slemma, signifie couronne des shamps.

Cormier. Voyez SORbier.

COUdrier, Vyez NoISETIER.

Consoude. Sentiment inaltérable.

C'est dans les prés humides de la France et d'une partie de l'Europe qu'habitè la corsoude qui fleurit depuis le mois de mai jusqu'en octobre; cette plante, d'un fréquent usage en médecine, sert à consolider les plaies. Ses racines profondes se multiplient tellement qu'on ne peut la détruire.

Corbeille d'or. Voyez Alysse des rochers.

CORIA NDRE. Mérite caché.

L'odeur insupportable de la coriandre n'empéche pàs que ses graines en mûrissant n'acquièrent lin 
p̧arfum aromatique très-agréable; elles servenť aixx confiseurs et aux parfumeurs. Cette plante dont les fleurs s'épanouissent en juin et juillet, est cultivée en plein-champ dans quelques provinces de la France.

Couronne impériale. Fierté.

On cultive la couronne impériale dans nns jardins qu'elle orne dès le commencement du printemps; ses fleurs disposées en couronne lui ont fait donner son nom.

\section{Croix-DE-JÉrusalem. Voyez LyCNide de Cal- cédoine.}

\section{CroiX-De-Malthe. $\quad I d$.}

Crysocome linosiris. Tous vous faites allendre:

C'est dans l'arrière-saison, lorsque les autres fleurs sont presque toutes passées, que la crysocome vient orner nos parterres; elle croît dans plusieurs parties de la France, et sur-tout aux environs de Paris.

\section{Cupidone bleue. Vous inspirez l'amour.}

La cupidone habite les lieux stériles et montagneux de la Provence; ses fleurs se montrent depuis le mois de juillet jusqu'en novembre. Les Grecs croyaient que cette plante inspirait l'amour, d'où lui est venu son nom. 
CYNoglossE printanière. Je suis votre meilleur ami.

On cultive la cynoglosse dans nos jardins où elle produit par son feuillage d'un vert tendre un effet très-agréable; ses fleurs naissent en mars et avril. Son nom vient de deux mots grecs qui signifient langue de chien.

CYPRÈs. Regrets, deuit, désespoir, mort.

Le cyṕrès dont le feuillage triste et lugubre inspire une sombre mélancolie, a de tout temps été regardé comme le symbole des regrets et de la mort; la sıture semble avoir fixé sa place autour des tombeaux. Les poëtes disent qu'Apollon changea en cyprès le jeune Cyparisse qui voulait se tuer. Cet arbre était consacré à Pluton et au dieu Sylvain.

Datura. Voyez Stramoine.

DAUPHINELLE d'Ajax, vulgairement PIEDD'AlouetTE. Lisez dans mon contr.

La dauphinelle d'Ajax offre une singularité remarquable dans son intéricur; on y voit les lettres $a-j-a$ par lesquelles commencent le nom d'Ajax: les anciens poëtes ont dit que ce prince, fils de Télamon, tut changé aprés sa mort en cette plante; elle fleurit dans nos jardins en juillet et août.

Dictame blanc ou Fraxinelle. Vous menflammez, vous embrâsez mon cceur.

Le dictame blanc croît dans les bois et les pâtu. 
rages montueux des parties méridionales de l'Europe et de la France; ; il fleurit en juin et juillet, et répand alors une odeur semblable à celle du citron. nier. Il en sort vers le soir une vapeur forte et éthć. rée qu'on peut facilement enflammer en approchan: une bougie allumée; cette flamme parcourt toute la plante sans l'endommager.

Digit a LE pourprée. Vous n'êtes que belle.

La famille naturelle de la digitale comprend plusieurs espèces de plantes vénéneuses; celle-ci quí fleurit en aoû́t et septembre est très-belle, mais n'est d'aucune utilité.

\section{Douze-Divinités. Voyez Girosetle:}

Eglantier. Voyez Rosier églantíer.

ENOTHÈrE à grandes fleurs. Inconstance.

La plante connue sous le nom d'énothère nous vient de Virginie; l'éclat et l'odeur de ses fleurs la rendent précieuse pour nos parterres; elles ne durent qu'un jour, mais elles fleurissent en grand nombre dans les mois de juillet, août et septembre.

EPHÉMÉRINE de Virginie. Bonheur d'un instant.

L'éphémérine donne de très-jclies fleurs qui ne durent que quelques heures, mais qui se succèdent depuis le mois de juin jusqu'en octobre. 
EPI de froment. Abondance.

L'épi de blé était chez les anciens le symbole du mariage.

« Le froment est sans contredit de tous les gra* minées qui couvrent la surface de l'Europe celui « qui mérite le plus notre admiration, le travail as* sidu des cultivateurs, et les soins que nous pre* nons de sa conservation; aussi la nature a-t-elle « accordé à ce végétal une sorte de prédilection, * en le faisant croître avec un égal succès dans « l'ancien et dans le nouveau monde, dans les cli" mat's chauds comme dans les climats froids." Parmentier, noupeau Dictionnaire d'Histoire nafurelle:

EPILовE a épi, ou Oster fleuri. Trnissons-nots:

L'épilobe à épi est une fort belle plante que $1^{\text {xon }}$ trouve dans les bois de la France et d'une partie cle l'Europe ; ses fleurs grandes, belles et d'une couleur rouge se montrent en juin; ses aigrettes peuvent se filer en les mêlant avec clu coton.

EPINES. Remords.

EPINevinette. Vous me fuyez."

L'irritabilité des plantes se fait singulièrement remarquer dans les fleurs de l'épinevinette; en touchant légèrement leurs étamines, elles se replient aussitôt du côté du pistil, Cet arbrisseau crổt en Europe, et fleurit au printemps. 
ERABLE de montagne, ou SYCOMORE. Harmonie.

L'èrable croît en France, en Suisse, en Allemagne, etc.; il fleurit au printemps. Les luthiers emploient de préférence le bois de sycomore marbré des montagnes pour faire les dos des violons et d'autres instrumens de ce genre.

\section{Eupatoire. Amour paternel.}

C'est ordinairement vers la fin de l'èté que fleurit l'eupatoire, plante aquatique. Les anciens l'avaient dédié à Mithridate, roi de Pont, surnommé Eupator, c'est-à.dire bon père.

EUPHORBE réveil-matin. J'ai perdlu le repos.

L'euphorbe dont les fleurs paraissent pendant la belle saison, se trouve abondamment dans les lieux cultivès et dans les jardins humides de la France et de l'Europe; elle est nommée réveil matin, parce que si l'on se frotte les yeux après en avoir touché, on ressent des démangeaisons qui empêchent de dormir.

FAYARD. Voyez HÊTRE.

FEUILLES vertes. Espérance.

De tout temps le vert a été consacré à l'espérance, sans doute parce que les feuilles nous annoncent les beaux jours. 
Ficoide cristallin, ou glaciale. Vous me glacez,

La glaciale que l'on cultive dans nos jardins est une plante très-singulière, à raison des gouttes d'eau glacées dont elle est couverte.

Figuier. Reconnaissance, hospilalité.

Le figuier, originaire de l'Asie et de l'Europe méridionale, est un arbre des plus intéressans que l'on connaisse, tant par la bonté de ses fruits que par la quantité qu'il rapporte; il en existe un grand nombre l'espèces qui donnent des fruits deux fois paran.

Les Athéniens avaient pour le figuier la plus grande vénération; ils en plaçaient des branches devant leurs portes pour présage d'un heureux retour lorsqu'ils se disposaient à un voyage : on en offrait en sacrifice d'expiation dans les villes affligées de la peste ou d'autres maladies épridémiques; il fut consacré à Mercure; on en couronnait Saturne. Les anciens ont lit que Cérès ayant voulu récompenser un Athénien de ce qu'elle en avait reçu l'hospitalité, lui avait fait présent d'un figuier.

Fleur de la Passion. Voy. Grenadille bleue.

Fleur de veuve. Voyez Scabieuse.

Fleur du Grand-Seigneur. Voyez Centaurés. musquée. 
Fleur d'une heure. Voyez Ketmie vésiculeuse.

Fougère. Incerlitude.

Les botanistes ne sont pas d'accord sur les parties de la fructification de cette plante.

Fraisier, Vous faites mes délices.

Le fraisier croît naturellement dans nos bois où il se fait remarquer par ses jolies et nombreuses fleurs blanches qui paraissent en mai, et sur-tout par ses fruits délicieux et parfumés; il est plus beau et plus fécond dans nos jardins. Le nom générique fragrare signifie exhaler de l'odeur.

Fraxinelte. Voyez Dictame blane.

FRỀNE. Tout est soumis à sotre empire.

Les poëtes ont dit que l'arc de l'amour était fait de bois de frêne; cet arbre qui crôit dans les climats tempérés de l'Europe, fleurit au printemps. Il était consacré à Mars.

FUMETERRE commune. Fiel, rancune.

On a donné le nom de fiel de terre à la fumeterre, parce qu'elle est d'un goût très-désagréable, et trèsamère; elle habite la France et une partie de l'Europe dans tous les lieux cultivés, et fleurit pendant la belle saison. 
Fusain. Jotre image est tracés dans mon cour.

On peut employer le bois de fusain pour la sculpture, mais il sert principalement à faire des crayons qui portent son nom; on le trouve en France, en Suisse, en Allemagne : il fleurit au mois de mai.

Galantine perce-neige. Annonce, heureux présage.

On trouve la galantine dans les prés et les mon. tagnes de la France; elle fleurit dès le retour du printemps, même lorsque la neige couvre encore nos campagnes. Reneaulme a clonné un nom grec à cette plante, qui signifie messagere cu printemps.

Gatilier commun, ou AgneAu chaste. Chasteté.

C'est dans les lieux humides et sur le bord cles rivières des parties méridionales de ls France que se trouve le gatilier commun, dont les fleurs paraissent en juillet et août. Les A théniennes consacrées au culte de Cèrès mettaient de cette plante sous leur couche pour conserver leur chasteté, ce qui lui fit donner son nom.

GENÊT d'Espagne. Je sais apprécier vos talens.

Le genêt d'Espagne que l'on cultive dans nos jarlins, fleurit depuis le mois de juillet jusqu'en septembre; ses rameaux fournissent des fils dont on peut faire de la toile. 
Gentiane jaune. Vous refusez mes soins.

C'est dans l'intérieur de la France que l'on trouve en abondance la gentiane jaune dont les fleurs paraissent dans la belle saison; cette plante est superbe, mais elle ne peut supporter la culture.

GÉRANIUM, Estime, amour flial, fidélité conjugale.

Géranium vient de geranos en grec, grue, bec de grue, bec de cigogne, parce que le fruit de cette plante est terminé par un long bec. Tout le monde connaît la cigogne, oiseau célèbre par ses qualités éminentes: la reconnaissance, la fidélité conjugale, la piété filiale et paternelle sont ses vertus morales.

GÉranium triste, Mélancolie.

C'est pendant la nuit que le géranium triste répand une odeur délicieuse de girofle; on le cultive dans nos jardins où il fleurit conme totites les autres espèces pendant une grande partie de la belle saison.

GESSE à larges feuilles, ou PoIs à bouquet. Plaisir.

Depuis long-temps le pois à bouquet décore les jardins de la France; c'est une très-belle plante dont les fleurs s'épanouissent en juillet et août. On regrette qu'elle soit inodore.

GESSE odorante. Délicatesse, plaisir délicat.

Tout le monde connaît la beauté et le parfura 
agréable du pois de senteur si fréquemment cultivé dans nos jardins; il fleurit à la même époque que le précédent.

GirofléE de muraille, ou Girofiée simple. Simplicité.

Quelques espèces de giroflée fleurissent de trèsbonne heure, d'autres un peu plus tą̧d; celle-ci, quoique très-commune, est cultivée dans les jardins, à raison de la bonzie odeur et de la quantité de ses fleurs.

Girof lée des jardins, ou Vrolier. Luxe.

La giroflée ou violier est une très-belle plante que tout le monde admire, tant pour sa beauté que pour l'odeur agréable de ses fleurs qui naissent en mai et se renuuvellent sans cesse jurqu'a la fin de l'été; elles solit blanches, rouges, violettes ou panachées.

GiRofléE de Mahon. Voyez Julienne maritime. Giroflée d'été, ou Quarantaine. Promptitude.

La végétation de cette espèce de giroflée est si prompte, qu'elle donne des fleurs au bout de quarante jours, d'ou lui vient son nom de quarantaine; en la semant à différentos époques, on a des fleurs tout l'été.

Giroselle ou les Douze-Divinités. Vous êtes ma divinité, je rous adore.

Le nom générique de la giroselle est furmé de 
deux mots grecs, dôdeca, douze, et theos, dieu; c'est-d-dire les douze divinités, parce que ses 凤eurs sont au nombre de douze. Cette jolie plante qui contribue à l'embellissement de nos parterres, fleurit en avril et mai.

Glaciale. Voyez Ficö́de cristallin.

Gouet commun. Ardeur.

Le gouet commun croît dans les bois et les lieus couverts le presque toute la France, et fleurit au commencement du printemps; à une certaine époque de sa floraison, le spadix de cette plante acquiert une si forte chaleur, qu'il est impossible de le toucher.

GOUET gobe-mouche. Piége.

Ce gouet est cultivé dans les jardins des curieux, à cause cle sa singularité. Lorsque les mouches atti. rées par sa mauvaise odeur sont entrées clans la cavité de sa fleur, elles n'en peuvent plus sortir.

GRATIOI.E officinale, ou HEr.BE au pauvre homme. Humanité.

Le nom générique gratiola vient de gratia, qui signifie fapeur, bienfait, à cause des vertus qu'on attribue à cette plante qui habíte les terrains humides de la France et d'une partic de l'Europe; ses fleurs se montrent en juin et juillet. 
GRENADIER. L'nion, concorde.

Nous devons à l'A frique le grenadier, arbre charmant qui commence à fleurir en juillet. On a consacré son fruit chez les anciens à l'union et à la concorde, sans doute à cause du très-grand nombre tle pepins brillans q̨u'il renferme.

Grenadille bleue, ou Fleur de la Passion. Croyance, foi, piété.

La grenadille est une très-belle plante naturalisée en France, dont les fleurs se succèdent depuis le mois de juillet jusqu'au mois d'octobre. Son nom lui vient de ce qu'on a cru y remarquer les instrumens de la Passion; elle présente des phénomènes extraordinaires au moment de son développement.

GROSEILIER. Vous me plaisez.

Il n'est personne qui ne connaisce le groseiller, joli arbrisse au dont les fruits sont si agréables à la vue et au goût.

\section{GUI commun. Liaison dangereuse.}

Le gui commun est un arbuste parasite qui fleurit au commencement du printemps, et qui croît sur le poirier, le pommier, le tilleul et le chêne; cette plante est très-nuisible aux arbres sur lesquels elle se trouve; ils en souffrent beaucuup, sur-tout lorsqu'elle $y$ est abondante. 
GUI de chẻne. Superstition.

Les chênes chargés de gui étaient choisis de préférence par les druides pour prier sous leur ombrage; leur respect superstitieux pour cette plante était tel, qu'ils la regardaient comme sacrée; ils coupaient les branches de ce gui avec une faux d'or, et après les avoir consacrées les distribuaient au peuple.

Guimauve. Douceur exirême, persuasion.

- La guimauve, plante très-commune indigène à 1 Europe, fleurit en juin et juillet, et croît ordinairement sur le bord des ruisseaux et dans les endroits humides; elle renferme un principe mucilagineux auquel on attribue toutes ses vertus.

Guirlandes de fleurs. Chaines d'amour ou d'amitie.

Selon les fleurs dont elles sont composées.

HÉLÉNIE. Pleurs.

Originaire des parties méridionales de l'Améri. que, l'hélénie contribue à décorer nos parterres dans l'arrière-saison par ses thuffes de fleurs jaunes; elle fut, dit-on, produite des larmes d'Hélène.

HÉLIANTHE à grandes fleurs, vulgairement TOUR N ISOL. Ires yenx ne royent que vous.

L'hélianthe est une très-belle plante cultis ée depuis long-temps en Europe, dont les fleuis qui pz- 
raissent en juillet sont le plus souvent dirigées vers le soleil, ce qui l'a fait appeler vulgairement tournesol. Son nom composé du grec helios et anthos veut dire fleur du soleil.

HÉLIOTROPE d'hiver. Voyez TUSSilAGE odorant.

HÉliotrope du Pérou. Je pous aime plus que moimême.

L'héliotrope est très-recherché pour son parfum délicieux; il aime be uucoup le soleil, et fleurit même en hiver lorsqu'il est dans une serre exposée au milli. Les poètes racontent que Clytie fut aimée d'A pollon, et conçut une telle jalousie de se voir abandonnée pour Leucothoée, qu'elle se laissa mourir de faim: Apollon la métamorphosa en héliotrope.

\section{HeLlÉEORE à fleur rose, vulgairement Rose de} Noel. Consolation.

La première plante qui fleurit dans les vallées et les nontagnes de la France, est l'hellébore à fleur rose; elle paraît en janvier et février, quelquefois vers la fin de décembre lorsque la nature est dépouillée de tous ses ornemens; le contraste de son feuillage sombre avec-la rose tendre de ses calices forme un ensemble des plus agréables, et semble être la pour consoler, en rappelant la saison des beaux jours. 
HÉMÉROCALLE rouge. Plaisir loujours nouveau.

Les fleurs de l'hémérocalle ne durent qu'un jour, mais elles se renouvellent pendant plusieurs mois; c'est une fort belle plante qui nous vient, dit-on, de la Chine. On la trouve en Suisse et au midi de la France.

HERBE au chantre. Voyez VÉLAR dès boutiques.

Herbe au pauvre homme. Voyez GRATIOLE officinale.

HERBE aux magiciennes. Toyez CircF́.

Herbe cachée. Voyez Clandestine.

HERBE d'amour. Voyez RÉSÉDA odorant.

Herbe sacrée. Voyez VERVEINE.

Hètre ou FayaRD. Prospérilé.

Le hêtre, bel arbre de nos forêts, peut être regardé comme le rival du chêne par la beautè de son port et par son utilité ; comme lui, il fut consacrè à Jupiter. Cet arbre vient très-promptement, et croît presque par-tout; il a été souvent chanté par les poètes. C'est de lui que Bernis a dit, dans son Poëme des Saisons:

« Cent ans il reponssa la guerre

«Des aquilons impétueux;

"Inébranlable et fastueux,

" Il foulait le sein de la terre; 
* Son front brûlé par le tonnerre

« En était plus majestueux.

* Quels dieux ont causé sa ruine?

« Un bîcheron faible et courbé

« A frappé l'arbre en sa racine;

« Le roi des forêts est tombé. »

Hortensia ou Rose du Japon. Beauté froide. Yous êles belle, mais fioide.

L'hortensia eqt une belle plante sans odeur, dont les fleurs d'une jolie couleur rose sont très-nombreuses, et se succèdent pendant une grande partie de l'èté.

Houx commun. Sauve-garde; protégez-moi, défendez-moi.

Le houx commun, toujours vert, habite presque toute l'Europe, et fleurit en mai et juin ; il est tièspropre a l'usage des haies vives : celles qui sont faites avec cet arbrisseau sont trés-défensives, de la plus longue durée, et respectées des insectes et des animaux.

IBÉRIDE, vulgairement TARASPIC. Indiff'rence.

L’ibéride qui fleurit en juin et juillet, est naturslisée dans presque tous nos jardins; ses fleurs sont nombreuses, mais sans odeur.

IF. Trislesse.

L'if est un arbre toujours vert, d'un aspect triste, 
qui croît naturellement en Europe; ses fleurs paraissent à la fin de mai. Il fut consacré à Cérès.

IMMORTELLE. Toujours, amitié ou amour sans fin ; éternilé.

Les immortelles se cultivent dans presque tous les jardins; elles fleurissent en été. Tout le monde peut clonner à ces fleurs la signification qui leur est propre, en l'attribuant au sentiment qu'on veut exprimer.

IFOMÉA, vulgairement JASMIN rouge. Je mallache à vous.

Depuis long-temps on cultive flans nos jardins l'ipoméa dont les tiges garnissent agréablement les treillages et les berceaux; ses jolies fleurs qui naissent en juillet, août et septembre, sont écarlates, et les feuilles vert foncé en dessus, et clair en dessous.

IPOMÉA pourpré, vulgairement VOLUBILIS. Caresses.

On cultive fréquemment dans nos jardins l'ipoméa: pourpré, dont le port est extrêmement élégant, et qui, s'élevant avcc grâce autour des appuis qu'on lui prête, semble les envelopper de ses caresses. Ses fleurs se succèdent depuis le mois de juin jusqu'au mois de septembre.

IRIS bulbeuse. Eloquence.

L'iris est naturalisée dans nos jardins, où ses fleurs 
s'épanouissent en juin et juillet; son port est d'un aspect noble; elle est sur-tout remarquable par la forme de ses pétales et par la variété de ses couleurs, ce qui lui a fait donner le nnm d'iris: les poëtes donnent ce nom à la messagère cles dieux, qu’ils représentent par l'arc-en-ciel.

IRIs de Perse. Message, raccommodement.

Cette iris est moins délicate que la première, et plus printanière; on voit ses fleurs belles et odoriférantes aux mois de février et mars.

IVRAIE OU ZIZANIE, Vice.

Livraie, plante très-malfaisante, croît à côté du froment, de l'avoine et de l'orge.

IXIA. Vous failes mon tourment.

L'ixia est une plante bulbeuse, dont la forme des fleurs rappelle la roue d'lxion. Il y en a d'odorantes qui se ferment le soir; d'autres, tel que le cinnamomum, répandent leur parfum pendant la nuit. et se ferment le matin ; elles fleurissent en différens temps suivant les espèces.

JACÉE des jardiniers. Voyez LyCHNIDE compagnon. JACINTHE orientale. V'ous m'aimez et vous me donnez la mort.

La jacinthe que tout le monde connaît, que tout 
le monde admire, mérite une des premières places dans nos parterres; elie a sur les autres plantes d'agrément l'avantage de former à elle seule un bouquet parfaik, par l'arrangement de ses fleurs autour sle sa tige; on peut en avoir en toutes saisons dans les appartemens, puisqu'elle végète aussi bien dans l'eau que dans la terre; cette fleur aimable et d'un parfum suave couronne nos cheminées pendant les hivers.

Le jeune Hyacinthe (disent les anciens poëtes), fut aimé passionnément de Zéphire et d'Apollon. Un jour Zéphire, jaloux de le voir jouer avec son rival, lui dirigea un disque à la tête, et le tua; Apollon le métamorphosa en fleur, qui porta depuis son nom dont on a fait celui de jacinthe.

Jasmin blanc. Vous êtes aimable.

On fait des berceaux et des treillages avec le jasmin blanc, plante charmante naturalisée en Europe, qui donne, depuis le mois de juillet jusqu'en octobre, des fleurs en grand nombre et d'une odeur délicieuse; elles servent à la parfumerie. Cet arbuste est un des plus agréables orıemens de nos parterres:

JASMIN-JONQUILLE. Je vous aime.

De tous les jasmins odorans celui-ci répand le parfum le plus exquis; ses feuilles toujours vertes font ressortir l'éclat de ses jolies fleurs, qui paraissent au 
milieu de l'été, et durent souvent jusqu'à l'entrée de l'hiver.

JoNC des champs. Docilité; je serai docile.

Le jonc des champs est très-commun dans nos prés secs, où ses fleurs sont des premières à paraître au printemps; presque tous les joncs setvent à faire des liens et des paniers.

JoNC épars. Eclaircissement ; éclairez-moi.

C'est dans les lieux humides, les marais et sur le bord des fossés que se trouve le jonc épars; on peut se servir de sa moële séchée pour faire des mèches aux lampes que l'on appelle veilleuses.

Jonc fleuri. Voyez Butome à ombelle.

Jouriarbe des toits. Vous êtes bienfaisante sans oslentation.

C'est sur les vieux murs, les toits de chaume et les lieux pierreux que l'on trouve la joubarbe, trèsutile en médecine, dont quelques espèces pourraient obtenir place dans nos jardins pour la beauté de leurs fleurs et de leurs feuillages.

JUJU BIER. Volre présence adoucit mes peines.

Le jujubier croît naturellement en Languedoc et en Provence, et montre ses fleurs au mois de juin; ses fruits nourrissans et agréables s'emploient en nédecine contre les irritations de la poitrine. 
JULIENNE maritime, vulgairement GIROFLÉE de Mahon. Je porls vois apec plaisir.

C'est dans les parties méridionales de la France, et dans les illes de la Seine et de la Marne près Paris, qu'habite la julienne maritime, dont les fleurs s'épanouissent en juin et juillet; elles sont lilas, et en si grand nombre, qu'elles laissent à peine voir leurs feuilles, ce qui la rend propre à faire des bordures dans les jardins.

KETMIE vésiculeuse ou trifoliée, vulgairement FLEUR d'une heure. Plaisir d'un moment.

Venise est la patric de la ketmie trificliée, qui croît facilement dans nos jardins, et dont les fleurs qui ne durent que quelques instans se renouvellent pendant trois muis de l'été.

Ketmie des jardins, ou la Mauve en arbre. Beauté toujours nouvelle.

La mauve en arbre est un joli arbrisseau qุue l'on cultive dans les jardins de l'Europe, à raison de ses belles et nombreuses fleurs qui se succèdent pendant plus de trois mois; elles sont variées des plus belles couleurs.

LAîCHe. Perfutie.

Rien de plus pernicieux que la laîche dont la feuille coupante ensanglante souvent la bouche dea 
bestiaux; elle se trouve dans les lieux aquatiques de l'Europe, et fleurit au printemps.

LAUrÉole, vulgairement BnIs-GeNTrL. Gentillesse, désir de plaire.

Empressées le nous plaire, les fleurs de la lauréole paraissent au commencement du printemps, avant ses feuilles; cet arbuste croît dans les bois montagneux de l'Europe. Ses baies sont recherchées des ciseaux.

LAURIER franc. Triomphe, gloire.

C'était de laurier qque les Grecs et les Romains tressaient des couronnes pour les guerriers vainqueurs dans les combats, et pour les hommes célèbres par lcurs talens distingués: il fut révéré chez les anciens qui l'avaient consacré à Apollon; depuis, on en couronna les poëtes. Les mythologistes disent que Daphné, poursuivie par Apollon, fut changée en laurier.

\section{LAURIER rose. Séduction.}

La forme élégante et la beauté des fleurs et du fevillage dlu laurier rose arrêtent l'œil et nous charment, mais il cache en lui un suc âcre et caustique, qui est un véritable poison; ce grand arbrisseau, toujours vert, croît naturellement en Provence, en Italie, etc.; il fleurit en été. 
LAVANDE, ou AsPIC. Répondez-moi.

On tire de la lavande une eau, qui est regardée comme un spécifique pour la perte de la parole clans certaines maladies. Cette plante aromatique qui fleurit au milieu de l'été, est très-soignée dans nos jarclins.

LICIET cultivé. Vos altraits me charment.

Le liciet est un très-joli arbrisseau de l'Europe, formant des haies charmantes à l'époque de sa floraison qui a lieu pendant l'été.

LIERRE. Tendresse réciproque; je meurs ou je m'altache.

Le lierre fut de tout temps célébrć par los poëtes; c'est un grand arbrisseau toujours vert, qui n'abandome pas, méme après lour mort, les arbres auxquels il s'attache, car il persiste à les cruurir de son. charmant feuillage; il a été cunsacré à Bacchus et à la déesse Hébé.

Lilas. Première émolion d’amour.

C'est clu levant que nous vient le lilas, charmant arbrisseau que l'on cultive depuis long-temps en Europe. On ne voit pas sans émotion ses fleurs d'une couleur tendre et d'une odeur déliciense orner les bosquets du printemps, et nous annoncer le retour cle la belle saison. 
LiN. Je sents tous vos bienfails.

C'est au lin commun que nous avons l'obligation de nos vêtemens les plus utiles, qui ensuite se convertissent en papier, dépositaire de nos plus chères pensées; on tire aussi du lin une huile que l'on em. ploie dans les arts. C'est ordinairement dans le mois de juin que l'on voit naître ses jolies fleurs bleues.

\section{Lis blanc. Pureté, grandeur, majesté.}

Depuis long-temps nous possédons dans nos jardins le lis blanc, originaire de la Syrie et de la Palestine: entre toutes les fleurs, il se fait remarquer par l'élégance et la majesté de son port, sa belle forme, le parfum, et le blanc éclatant de ses pétales qui paraissent dans toute leur parure au milieu cie l'été. Dans l'antiquiré, il fut consacré à Junon; depuis, il a été choisi pour figurer dans l'écusson de nos Rois. C'est à une ode à la Vierge que l'on donne le lis d'argent dans les Jeux floraux.

\section{LISERON. Enchaînement; vouls m'enchaînez.}

Les jolies fleurs du liseron tapissent les haies, forment des guirlandes, et s'attachent amoureusement à l'appui qui les avoisine; cette plante habite la France, l'Europe, et fleurit depuis le mois de juin jusqu'en septembre. Son nom générique, convolvulus, signifie enlortiller. 
LISERON tricolore, OU BELLE-DE-JOUR. Coquetterie?

La belle-cle-jour paraît en juin; c'est un des pius beaux ornemens de nos parterres, à raison de la beauté et cle l'abontlance de ses fleurs qui s'ouvrent le matin et se ferment au soleil couchant, depuis juin jusqu'en septembre.

LU PIN varié. Vous rendez le calme à mon ame.

Le lupin varié se trouve dans le midi de la France, et fleurit en juin et juillet; une des espèces fut trèsestimée des anciens qui en mangeaient les graines préparées. Suivant le rapport de Pline, Protugène ne vécut que de lupin, pendant qu'il travaillait au chef-cl'œurre de Jalyze, afin d'être maître de son génie.

LUZERNE arborescente. Les bonnes actions survipent aux siècles.

On croit que la luzerne arborescente est le cythise de Virgile, qui fut en honneur chez les anciens, sans doute à cause des qualités essentielles qu'elle possède. On la place aussi dans les jardins à raison de la beauté de son feuillage.

LYCHNIDE compagnon, ou JACÉE des jardins. Je ne puis vous quiller.

La lychnicle compagnon s'appelle ainsi de ce que 
les panicules sont toujours de deux en deux; c'est une assez jolie plante de nos prés secs, dont on cultive une varièté à fleurs doubles blanches, ou d'un beau rose, qui ressemblent assez à un œillet, et qui paraissent en mai et juin.

LyChNide de Calcédoine, vulgairement Cror:de-Malthe, CroIX-DE-JÉrusalem. Fidélité à loute épreuve.

Quoique sans odeur, la lychnide de Calcédoine est cultivée dans nosjardins pour la couleur brillante de ses fleurs qui paraissent en juillet. Sa corolle a servi de type à la croix-de-Malthe.

Marguerite paquerette. Vous êtes jolie.

La paquerette est une jolie petite plante, qui fleurit dans nos prés vers le temps de Pâqques; on en cultıve des variétés de différentes couleurs, qui donnent des fleurs très-long-temps. Son nom latin bellis, de l'adjeçif bellus, signifie gentil, mignon.

Marjolaine vulgaire. Séchez yos larmes.

On cultive la marjolaine vulgaire dans nos jardins pour sa bonne odeur et ses qualités aromatiques; elle fleurit en juillet. Ses feuilles servent à faire un poudre que l'on inspire par le nez; elle est employée dans le larmoiement par abondance d'humeur séxeuse. 
MAUve, arbre. Voyez KeTMIE des jarclins.

MaUve grande. Amour matemel.

La grande mauve comprencl un grand nombre d'espèces communes à l'Europe, qui fleurissent en août, septembre et octobre; on trouve celle-ci dans les lieux incultes, les décombres, le long des haies et des chemins; elle est très-utile en médecine : on dit que la décoction de ses feuilles et de ses racines avec du fenouil et de l'aneth, donne beaucoup de lait aux nourrices.

MÉLìze. Audace : volre audace m'étonne.

Le mélèze, arbre résineux qui c roît naturellement dans les Alpes et les Apennins, et dans toutes les grandes chaînes de montagnes, s'élève à une hauzeur prodigieuse. Les naturalistes l'ont nommé le géant des arbres d'Europe.

MÉLISSE officinale. Soupenez-yous de moi.

La mélisse officinale qui fleurit en juin et juillet, croît le long des haies et des chemins. On la cultive dans les jardins à raison desa bonne odeur et de ses vertus médicinales; on en fait usage dans toutes les maladies nerveuses, la faiblesse de mémoire, la mélancolie, etc.

Menthe, ou Baume des jardins. Vertu.

C'est en été que fleurit la menthe, plante vivace 
đe l'Europe, qui est très-fréquemment employée en médecine à raison des grandes vertus qu'on lui attribue.

MignaRdise. Voyez Fir.tet musqué.

Millefeurlite. Foyez Achillé.

Mir.lepertuis. Oubli; oublions le passé.

Le millepertuis fleurit en été ; il est très-répandu dans nos jardins pour ses propriétés médicinales.

«On rapporte à cette espèce une plante cueillie " dans la partie de la Tartarie qui borde la Chine; " les habitans de ces contrées où les liqueurs fer" mentées sont inconnues, cherchent leurs plus " douces jouissances, ou plutôt l'oubli cle leurs maux, " dans une infusion de cette plante qui fait sur eux. 3. l'effet d'un puissant narcotique. "Nouveau Dict. a'Hisloire naturelle.

Miroir de Vémus. Voyez Campanuze:

\section{Mogor.. Parure.}

Les femmes de l'Inde se parent avec des guirlandes de mogori, et se parfument de l'huile que l'on extrait de ses fleurs, qui ont une odeur suave et douce approchant du muguet et de la fleuz d'orange. Cet arbrisseau fleurit presque toute l'annce dans nos jardins. 
MOLÈne, vulgairement Boulllon-BlaNC. Bon nalurel.

La molène qui donne ses fleurs pendant la belle saison, se trouve dans toute l'Europe sur le bord des chemins, dans les champs et les lieux pierreux; elle est émolliente, adoucissante, calmante, antispasmodique : on l'emploie dans toutes les inflammations.

Momorbique piquante. Colère, emportement.

Les fruits de la momordique piquante renferment une humeur visqueuse, qu'ils lancent avee leur semence lorsqu'ils sont mûrs, et qu'en les touchant ils se sont détachés de leur pédoncule, ce qui la fair cultiver par curiosité. Cette plante se trouve dans les parties méridionales de la France, et fleurit en juin et juillet.

Morelie-Certsette, ou Amum des jardiniers: dans quelques pays POMME d'amour. Beauté sans bonté.

Le feuillage élégant de la morelle-cerisette est presque toujours vert; on la cultive fréquemment dans nos jardins, où l'on voit éclore ses fleurs en juin, juillet et août : ses fruits ressemblent assez a la cerise pour la couleur et la forme.

Mofet,le douce-amère, ou Vigne-Vierge. Sincérité, franchise, vérité.

Cette espèce de morelle qui fleurit en juin, est 
très-jolie, et se trouve dans les lieux humides, au milieu des haies et des buissons qu'elle orne de ses charmantes fleurs: son nom lui vient de ce que ses feuilles ont une saveur douce et amère.

Mousses. Sensations douces, sensations heureuses.

« Déjà les fleurs ont disparu, les feuilles se déta» chent, et sont balayées par les vents du nord: "leur éclat s'est terni; elles ont pris par avance la " couleur uniforme et triste de la poussière dans " laquelle elles vont rentrer; l'hiver enfin déploie " toutes ses rigueurs; il jette sur la terre un voile " de neige; tout a passé, tout a péri, et la faible " mousse se conserve plus verdoyante que jamais; le " printemps ne dédaigne pas sa tendre parure, et "l'enlace à sa superbe et brillante couronne." Bosc, nouvean Dict. d'Histoire naturelle.

MUflier des jardins, vulgairement Mufle de veau. Présomiption.

Le muflier dont on voit les fleurs en juin, juillet et aoutt, se cultive pour la variété de ses couleurs, qui produit un assez joli effet; cette plante très-rustique se propage d'elle-même; presque tous les terrains lui conviennent. Le grand nombre de pieds fournis par ses graines la rend très-incomrnode.

MÚGUET de mai. Retour du bonheur; soyons heureux. Au commencement du mois de mai, les fleurs 
charmantes du muguet paraissent dans nos bois, et viennent remplacer la modeste violette; elles semblent destinées à orner le sein de la beauté par leur jolie forme et leur odeur suave.

Muguet anguleux, vulgairement SCEAU de Salomon. Discrétion, secret.

Cette espèce de muguet crô̂t dans nos bois comme le précédent; il aime l'ombre et la solitude : on remarque sur les nouds de sa racine des empreintes de cachet, ce qui lui a fait donner son nom vulgaire.

Mi'RIER blanc. Prodige, merveille,

Le murier blanc, arbre naturalisé en Europe, est le plus généralement cultivé pour les vers à soie. Prodige ét mnant de la nature, il contient et fournit les élémens qui procurent ces étoffes si douces et si belles dont se pare la beauté.

MURier noir. Je ne vous survivrai pas; mourons ensemble.

Le fruit de ce murier est beaucoup plus gros que celui du murier blanc; cet arbre est célèbre dans la Fable.

Thisbé avait donné rendez vous à Pyrame sous un murier: s'y étant rendue la première, elle s'enfuit à l'approche d'une lionne dont la gueule était ensanglantée, et laissa tomber son voile que la lionne déchira et teignit de sang: Pyrame arrive, il croit 
son amante dévorée, et se tue de désespoir; Thisbé revient bientôt après, voit Pyrame expirant, et se perçant le sein avec le même fer, tombe mourante sur le corps de son amant. Les fruits de ce murier devinrent noirs de blancs qu'ils étaient.

MYosotis. Ne m'oubliez pas.

La myosotis est une jolie petite fleur bleue qui se trouve dans les prairiés et les lieux aquatiques; elle fleutit depuis le mois d'avril jusqu'au mois d'aô̂t. Le nom que les Allemands lui donnent, signifie ne m'oubliez pas, parce qu'ils ont l'habitude de l'offrir en gage d'amitié, et qu'elle se conserve facilement dans un livre comme la violette-pensée.

\section{MYRTE. Amour; tout amour.}

Le myrte commun qui croît en France, est un charmant arbrisseau dont le feuillage toujours vert contraste agréablement avec ses jolies fleurs blanches qui paraissent en été.

“ Les poëtes le consacrèrent à la déesse des s amours. Le peuplier, dit Virgile, plaît a Alcide, " la vigne à Bacchus, et le myrte à la belle Vénus. "Enée assistait aux jeux le front ceint du myrte " de sa mère. La muse Frato qui présiclait aux " poésies amuureuses, et tous les puëtes élégiaques, " étaient couronnés le ses feuilles. Virgile a placé

» dans les enfers un bosquet de inyrte où errent !es 
* ames amoureuses : les auteurs ne sont pas d'accord

* néanmoins sur la raison qui fit consacrer le myrte

" à Vénus; quelques-uns ont cru que la déesse, au

3) moment de sa naissance, et lorsqu'elle séchait ses

" beaux cheveux près des bords le la mer, ayant

» été apperçue par les satyres, se déroba à leurs

" regards en se cachant sous des myrtes; d'autres

" ont pensé que c'était parce qu'elle se couronna

" de feuilles de myrte après sa victoire sur Junon

" et sur Pallas. " Planles de la France, par M. Jaume-

Sainl-Hilaire.

NarCISৎ̣ des poëtes. Faluité, faux amour; vous n'aimez que vous.

C'est au mois de mai que fleurit le narcisse, jolie plante qui fait l'ornement des parterres et des salons.

Le beau narcisse (disent les mythologistes) était aimé de toutes les nymphes; il n'en écouta pas une. Écho ne pouvant le séduire, en sécha de douleur: un jour qu'il se regardait dans une fontaine, il clevint si épris de lui-même, qu'il mourut de langueur; il fut métamorphosé en la plante qui porte son nom. Les anciens la consacrèrent à Pluton, à Proserpine, aux Euménides et aux Furies.

\section{NARCISSE-JONQUILLE. Langueur d"amour.}

Le nom de jonquille a été donné à ce narcisse, parce que ses feuilles ressemulent à celles du jonc. Il crô̂t naturellement en Europe, et flourit en avril; 
son parfum exquis embaume délicieusement les jardins; mais, renfermée dans un appartement, cette fleur, d'une odeur trop forte, nuit aux personnes dont les nerfs sont délicats.

Nénuphar, ou Nympééa blanc. Froideur.

Le nénuphar qui croît sur les étangs, donne de très-belles fleurs qui s'épanouissent en mai, et durent quelquefois jusqu'en automne; elles paraissent le matin à la surface des eaux, et se plongent tous les soirs dans leur humide habitation. Cette plante, employée en médecine, est éxtrêmement rafrâ̂chissante, mais nuisible à l'estomac.

\section{Nerprun. Garantie.}

C'est en Europe, dans les haies, les bois et les lieux incultes que vient le nerprun, arhrisseau dont le feuillage est toujours vert, et qui fait d'excellentes clôtures. Ses fruits, lorsqu'ils sunt bien mûrs, donnent une belle couleur verte.

Nictage, vulgairement BeLLE-DE-Nuit. Je fuis, je redoute l'amour. Pourquoi fuir, pourquoi redouter l'amour?

La belle-de-nuit uaturalisée en France se montro en juillet et août; elle ne s'épanouit qu'a l'entrée de la nuit, et se referme aux premiers rayons du soleil. 
Nigelle de Damas, vulgairement Caeveux de Vènus. Les tresses de vos cheveux sont aulant de chaînes pour mon caur.

La plante connue sous le nom vulgaire de cheveux de Vénus, fleurit depuis le mois de juin jusqu'en septembre; elle se fait remarquer dans nos parterres jar ses fleurs d'un beau bleu céleste, entourées de filets verts assez semblables à des cheveux, ce qui lui a donné son nom vulgaire.

Nrvéole printanière, vulgairement PERCE-NEIGE. Premier regard d'amour, premier soupir d'amour.

C'est ordinairement aussitòt après la fonte des neiges que paraît la nivéole printanière; on la trouve sur le borll des ruisseaux, dans les prés, où elle se monire en si grande quantité, que le terrain en est couvert comme d'un tapis.

NoISETIER ou COUdrier. Erreur, préfugís.

Le noisetier donne des fruits connus de tout lo monde; ses fleurs paraissent en février avant les feuilles: la flexibilité de son bois le rend propre à faire des cercèaux ; c'était de coudrier que l'on faisait les baguettes divinatoires, avec lesqquelles on prétendait découvrir les mines, les sources d'eau, etc.

Noyer. Irous possédez des qualités essentielles.

Le noyer est un arbre très-répandu en Europe; 
son bois est très-utile aux arts, ainsi çue l'huile qu'on tire de son fruit.

Cirllet des jardins. Amour pur; vous inspirez les senlimens les plus purs.

Dianthus, nom générique de l'œillet, veut dire Fleur de Jupiter, ou Digne des Dieux.

Cette belle plante qui orne tous les jardins, et qui charme également la vue et l'odorat, tient un rang distingué parmi toutes celles de nos parterres; ses fleurs se suscèdent pendant toute la belle saison, et réunissent la clurée à la beauté et au parfuın.

«Quelle essence, quelle ambroisie

"Autour de moi remplit les airs?

"Des plus doux parfums de l'Asie

"Les trésors me sont-ils ouverts?

"Suis-je sur les heureux rivages

* Où le frais Elisée, aux sages

"Offre ses oulorans bosquets ?

"Suis-je dans la céleste troupe

"Admis à partager la coupe

ע Qui circule aux divins banquets?

"Aimable œillet, c'est ton haleine

"Qui charme et pénètre mes sens;

* C'est toi qui verses dans la plaine

"Ces parfums doux et ravissans.

"Les esprits embaumés qu'exhale

》La rose fraîche et matinale 
" Pour mni sont moins délicieux;

3. Et ton odeur suave et pure

"Est un encens que la nature

" Elève en tribut vers les cieux."

Tes Fleurs, Idylles morales, par $M$. Constant Dubos.

OEILlet musqué, vulgairement MigNaRdisE. Soupenir passager.

Ce joli petit œillet paraît avec les premières fleurs du mois de mai, et disparaît avec elle.

EILlet de poëte, vulgairement BovQuet parfait. Vous êtes un assemblage de perfection.

La fleur du bouquet parfait offre des touffes charmantes qui figurent admirablement dans les parterres, vers le milieu de l'été.

Cirlet d'Inde. Poyez Taget.

Eillet mignonette, CEIlLET plume. Enfantillage.

Cet œillet, ur des plus jolis, est très-varié dlans ses couleurs; il répand une odeur agréable qui se fait sentir plutôt le matin que le soir.

Olivier d'Europe. Paix.

L'olivier est un arbre toujours rert, dont tout le moncle connaît l'utilité. Une branche d'olivier fut toujours donnée et reçus en sigrne de paix. Les anciens l'ont consacrè à Minerve. 
Ophrise araignẻe. Adresse.

OPHRISE mouche. Indiscrétion.

Il y a une grande quantité d'ophrises; celles-ci sont remarquables en ce que les fleurs représentent, l'une une araignée, l'autre une mouche; on les trouve dans les pàturages secs où elles sont très-communes; elies fleurissent en avril, mai ou septembre, suivant les variétés.

Oranger, la fleur. Pureté, candeur, virginité.

Le fruit. Beauté, bonté.

Si le blanc éclatant des fleurs de l'oranger, et son beau feuillage d'un vert tendre, flattent agréablement la vue, quelle sensation délicieuse ne procure pas son odeur suave et salutaire? L'air en est embaumé; et bien différente des fleurs dont l'oleur forte fatigue les nerfs, elle porte sur nos sens un calme bienfaisant. Il fallait que ce bel arbre eût encore des droits à notre amour, en nous domnant ce beau fruit doré quî séduit également la vue, le gunt et l'odorat : de même que la rose possède l'empire ile Flore, l'urange est le fruit favori de Pomone; symbole de la candeur et de l'innocence, la fleur d'orange sert de couronne à la jeune vierge qui narche à l'autel de l'hymen.

Les pcëtes prétendent que les oranges étaient les pummes d'or des Hespérides gardées par un dragon qu'Hercule tua poux en cueillir. 
ORIGAN dictame. Tous seule poupez guérir mon cour. L'origan cultivé en France fleurit en juin et juillet; il était très-connu, et avait la réputation chez les anciens d'attirer le fer des blessures.

M. Delille a traduit ainsi ces vers de Virgile:

" Aussitôt du héros dont Ia force succombe,

"La mère en gémissant va cueillir sur l'Ila,

"Cette herbe que le ciel à nos maux accorda,

"Le dictame sacré, poussant de sa racine

"La feuille cotonneuse et la fleur purpurine,

" Tout ressent son pouvoir; et quand le daim blessé

"Empoite au fond des bois le trait qui l'a percé,

"Suivant et le besoin et son instinct pour maître,

" Parmi cent végétaux il sait le reconnaître. "

ORME, OU ORMEAU. Considéralion, distinction, respect.

L'orme est un arbre de la première grandeur, qui croît par-tout en Europe. Il était cher à nos ayeux, qui le plaçaient autour de leurs habitations, et notamment à la porte des églises : ses semences se développent avec une promptitude remarquable; il est extraordinairement fécond, et vit plusieurs siècles.

ORNITHOGALE à ombelle, ou BELLE d'onze heures. Votre vue cause ma joie.

Autrefois l'ornithogale s'appelait heliocharmos, de Eeux mots grecs, helios, soleil, et charma, ce qui 
cause la joie: cette plante fait de très-jolies bordures; ses fleurs qui s'épanouissent en mai, s'ouvrent à onze heures, et se ferment à trois; elles sont blanches et d'une odeur agréable.

ORNITHOGALE pyramidal, vulgairement EPI de lait, EPI de la Vierge. MI a tendresse est pure.

Ornithogale vient de deux mots grecs, ornithos, génitif, d'ornis, oiseau, et gala, lait ; ce qui indique la forme de panache et la couleur de ces plantes. Celle ci dont la tige élevée se termine par une trèsbelle grappe de fleurs blanches étoilées, paraît en juin, et produit au coup-d'œil l'effet le plus agréable.

ORове printanier. Besoin d'aimer.

A peine l'influence du printemps se fait-elle sentir, que l'on voit paraître l'orobe printanier, qui se fait remarquer par son feuillage élégant et par le grand nombre de ses fleurs purpurines. On le cultive dans nos jardins.

Ortite. Je suis piqué, ou piquée.

Il n'e t personne qui ne connaisse les orties, et qui n'ait senti leurs piqûures.

Ozier fleuri. Voyez E pilobe à épis.

Paliner. Vicloire, constance dans i'adversité.

Le palmiste et le dattier sont les seules espèces 
de palmiers que l'Europe possède, encore les fruit, n'y viennent que difficilement; ces arbres majes. Eueux, d'un feuillage toujours vert, habitent les pays entre les tropiques, et fournissent aux peuples de ces contrées tous les premiers besoins de la vie; non-seulement ils peuvent les loger, les nourrir et les vêtir, mais encore ils offrent pour satiffaire le luxe, des avantages que nul autre arbre ne possède.

Dans l'antiquite, une branche de palmier ètait l'emblême ile la constance dans l'adversité, à raison de sa force végétative qui lui fait vaincre tous les ob tacles qu'on pourrait opposer à sa croissance.

Cet arbre fut consacré aux Muses.

Paquerette. Foyez Marguerite.

PaRnassie. Vous êles dans le sentier de la gloire.

La parnassie est ainsi nommée, parce que les an. ciens disaient l'avoir trouvée au bas du mont Parnasse; c'est une petite plante qui émaille agréable. ment nos prairies de ses jolies fleurs blanches, tachetées de jaune.

Passevelours crête de coq. Vos soins me rendent la vie.

Les passevelours nous viennent de l'Inde; ce sont de belles plantes, mais qui sont inodores: les amateurs les funt sécher au four, et lour font reprenúre dans l'hiver leur premier éclat, en les faisant tremper dans de l'eau tiècle. 
Pavot rouge, ou Coquelicot. Repos, calme de l'ame.

Le coquelicot est extrêmement répandu dans nos champs, parmi nos blés, où ses fleurs paraissent en juin et juillet; il passe pour sudlorifique et calmant. Les anciens l'avaient consacré à Cérès et à Lucine.

PAVOT somnifere ou des jardins. Sommeil.

Le pavot somnifère est une fort belle plante qui orne nos jarlins; on le cultive en grand dans quelques pays pour la graine dont on fait l'huile d'œillette ou de pavot: on extrait aussi l'opium de ses têtes.

PÊCHer. Plus je vous vois, plus je vous aime.

Le pêcher, arbre originaire de Perse, est acclimaté en Europe; son fruit, un des meilleurs que nous connaissions, plaît généralement à tout le monde: il est agréable à la vue, au toucher, au gon̂t et à l'odorat.

Pensée. Voyez Vrolette-Pensée.

Perce-Neige. Toyez Galantine et Nivéole printanière.

Pervenche. Amilié de toute la vie.

On trouve la pervenche dans les bois, dans les haies, parmi les broussailles, dans les fossés, et tous les lieux couverts, où les nøuds de ses rameaur 
s'aitachent furtement à la terre et $s^{\prime} y$ cnracinent; son nom latin vinca est tiré clu verbe sincire, qui signifie lier.

Cette fleur fut chérie de J. J. Rousseau.

\section{Peupler. Plaintes, murmures.}

Le peuplier balance sa tête majestueuse sur le bord des eaux ou il se plait; lo bruit de ses feuilles agitées par le zéphyr rappelle les plaintes des scnsibles Héléades qui, incornsolables de la mort de Phaéton leur frère, furent métamorphosées en peupliers.

Cet arbre fut consacré à Hercule.

Phytolacca dix étamines, vulgairement raisin d'Amérique, Calmez-yous.

C'est d'Amérique que nnus vient le phytolacca, naturalisé dans plusieurs cartons de la France; on a l'agrément de voir sur sa tise, pendant huit mois de l'année, des feuilles et des fleurs nouvelles: l'extrait de ses feuillos s'emploie dan, la composition du baume tranquille.

Pifd d'alouette. Voyez Dauphinelie d'Ajax. Pin. Longue durée, sentiment durable.

L'emploi que l'on fait du bois et de la résine du pin, arbre toujours vert, le font regarder comme un des plus utiles de ceux indigènes à l'Europe; il vit 
jusqu'à trois ou quatre siècles, ce qui l'avait fait consacrer à Cybèle, déesse de la terre; il fut aussi consacré au dieu Pan et au dieu Faune.

FISSENLIT. Légèrété, étourderie, inconséquence.

Le pissenlit est extrêmement répandu sur toute la surface du globe; on le trouve par-tout, dans les marais, comme sur les plus hautes montagnes; il fleurit toute l'année.

Tout le monde connait la forme de ses semences avec lesquelles les enfans jouent en les soufflant au vent.

Pivoráe. Tha beauté plaît, et les qualités essentielles allachent.

C'est au commencement de la belle saison que la pivoine vient orner nos parterrıs; elle e:t une des plus anciennes plantes connues en nédacine. $\mathrm{O}_{2}$ dit que le médecin Paeon, d'où elle tire son nom de pceonia, fut le premier qui fit connaître ses vertus; chez les modernes, ses grandes et nombreuses propriétés lui ont conservé sa célébıité.

Platane. Génie.

Le platane est un des plus beaux arbres que l'on connaisse; il réunit la majesté, l'élégance et l'élévation à la clurée et à la force. Les ancięus Grecs en faisaient le plus grand cas, et le cultivaient avec soin; il était pour eux un objet de culte : les tameur 
portiques où s'enseignaient les sciences et les mœurs, étaient précédés de grandes allées de platane; cet arbre était consacré aux génies et aux plaisirs.

POIRIER. L'éducation a développé pos bonnes qualilés.

Les pays tempérés comme celui de la France conviennent le mieux au poirier; la culture a rendu ses fruits doux, d'âpres qu'ils étaient dans son état sauvage, et lui a fait perdre ses épines.

PoIs à bouquet. Voyez GESSE à larges feuilles.

PoIs de senteur. Toyez, GESSE odorante.

POLÉMOINE bleue, vulgairement VALÉRIANNE grecque. Guerre, ruplure.

Suivant Pline, plusieurs rois se sont disputés l'honneur d'avoir trouvé la polémoine, ce qui lui fit donner le nom le polémos, mot grec qui signifie guerre; cette jolie plante qui fleurit en mai, juin et juiliet, embellit nos jardiris par ses jolies fleurs bleues et son charmant feuillage.

Pomme d'amour. Woyez Morelle-Cerisette. Pommier. Choix, préférence, à la plus belle.

Les pommiers comprennent un grand nombre d'espèces dont les fleurs viennent au mois de mai, et sont rasєemblées en bouquets rosés. 
Tout l'Olympe avait été invité aux noces de Théti et de Pélée; toutes les divinités infernales, aquatiques et terrestres y étaient, excepté la Discorde qui, pour s'en venger, jeta sur la table une pomme d'or, sur laquelle était écrit, à la plus belle. Junon, Pallas et Vénus la disputèrent: Pâris, chargé par Jupiter de terminier la querelle, adjugea la pomme à Vénus.

La signification que je donne au pommier, dont une espèce porte le nom de pomme d'or, peut également convenir au fruit de l'oranger.

Primevíre. Aimons-nous.

Le nom de la primevère signifie première fleur du printemps; en effet, on voit paraître, dès le commencement de mars, cette jolie petite plante qui vient nous annoncer les beaux juurs.

PRUNIER. T'enez pos promesses.

Tout le monde connât le prunier', arbre originaire de la Syrie et de la Dalmatie, naturalisé dans toute l'Europe; ses fleurs qui précèdent les feuilles, semblent empressées de nous annoncer ses fruits.

Quarantarne. Voyez Giroflée d'été.

Raisin d'Amérique. Voyez Phytolacca.

ReIne-Marguerite. Voyez Aster; voyez ChrYSANTHÈME des prés. 
RENONCULE âcre, bouton d'or. Critique, raillerie.

Le bouton d'or renferme un suc très-âcre ; cette plante d'Europe fait un assez joli effet, cultivée; on voit éclore ses fleurs au mois de mai.

RENONCULE scélérate. Méchanceté, ingratitude.

Le nom de cette renoncule suffit pour indiquer que l'on doit s'en méfier; c'est la plus malfaisante de toutes les plantes de nos prairies: elle fleurit en mai et juin.

Renoncule des jardins. Lustre, brillant, éulat. Dous brillez de mille atlrails.

C'est au mois de mai que les renoncules brillent de tout leur éclat; peu d'autres fleurs offrent une variété aussi piquante, et rien ne flatte plus agréablement la vue que l'aspect d'un parterre qui en est frarni.

RÉSÉDA odorant, vulgairement HEREE d'amour. Vos qualités surpassent vos charmes.

Le réséda fleurit en juillet et août; il n'offre rien de bien agréable a la vue, mais on le cultive a cause de son parfum, que Linnée compare à celui de l'ambroisie.

Romarin. Totre présence a dissipé le trouble de mon ame.

Le romarin, plante aromatique très-répandıo 
rans nos jardins, fleurit au commencement du printemps; on lui attribue la propriété de purifier l'air, en la brûlant avec du genièvre. L'eau que l'on retire de ses feuilles, dite eau de la Reine d'Hongrie, $s^{\prime}$ emploie dans les vertiges et les défaillances.

RONCES noires. Injustice, envie.

Les ronces croissent principalement dans les haies et dans les bois; elles nuisent beaucoup aux autres arbustes épineux, parce que leurs tiges rampantes s'emparent de tout le terrain.

Roseau canne, ou des jardins. Plaisirs champêtres.

Le roseau produit l'effet le plus pittoresque autour des pièces d'eau et dans les grands bosquets oul il figure agréablement; ses fleurs, d'une jolie couleur purpurine, paraissent avec grâce au sommet de leurs tiges: on fait avec ses cannes des hanches de haut-bois, de musette, et des chalumeaux. Ovide a dit que la nymphe Syrinx, poursuivie par Pan, dieu des bergers, "fut métamorphosée en roseau que ce dieu coupa ensuite pour en faire sa première flutte.

Roseau plumeux. Indiscrélion.

On trouve ce roseau dans les lieux couverts et dans les marais des bois. La mythologie nous apprend que Midas, Roi de Phrygie, ayant trouvé le chant du dieu Pan et de Marsias plus beau que celui d'Apollon, ce dieu lui fit venir des oreilles d'âne; 
un jour le barbier de Midas les apperçut en rasant ce Roi; ne pouvant garder son secret, mais craignant d'être puni s'il le divulguait, il fit un trou dans la terre ou il se débarrassa de ce fardeau; peu de temps après, il crût en cet endroit des roseaux qui, agités par le vent, répétaient sans cesse: le Roi Midas a des oreilles d'âne.

\section{Rose de Noël. Voyez Hellébore.}

Rose du Japon. Voyez HoRTENse.

ROSE trémière, ou ALCÉE. Votre beauté est noble et majestueuse.

La rose trémière, originaire de la Syrie, est une superbe plante d'un port pyramidal, et qui par cette raison peut embellir les grands jardins; ses flcurs sont grandes, variées, et dureıt fort long-temps.

ROSIER à cent feuilles. Beauté parfaile.

"Qui ne connaît, qui n'a point admiré cette fleur, " que toutes les belles chérissent, que tous les amans 》 recherchent, et que tous les poëtes ont chantée? "Anacréon l'appelle le doux parfum des dieux, la » joie des mortels, le plus bel ornement des grâces. * La rose, dit Sapho, est l'éclat des plantes, l'émail " des prairies; elle a une beauté ravissante qui at" tire et fixe Vénus, etc. etc.

* La rose renaît chaque printemps, et chaque 
" printemps elle nous paraît nouvelle. Quoique la " moins rare des fleurs, elle est toujours la plus " recherchée; au milieu de cent autres qui étalent "leurs beautés dans un parterre, c'est toujours elle " que nous allons cueillir cle préférence, et les épines " qui la défendent ne servent qu'à rendre plus vif ") notre désir de la posséder. Faut-il s'en étonner?

"Cette aimable fleur appelle et charme à-la fois tous "les sens. La douceur et le velouté de ses pétales " plaît au toucher; sa couleur enchante les regards; " et l'arôme pur qui s'exhale de son seín, flatte dẹ" licieusement l'odorat. Enfin, la rose a, dans son " port, dans son aspect, dans tout ce qui la cum- pose, je ne sais quels attraits qui manquent à " toute autre fleur, et qui nous séduisent, etc. * Dutour, nouveau Dict. d'Histoire nalurelle.

Rose blanche. Beauté innocente.

ROSE de mai. Amabilité.

ROSE des quatre saisons, ou de tous les mois. Beauté brillante et passagère.

ROSE en bouton. Cour qui ignore l'amour.

ROSE musquée. Beauté capricieuse.

ROSE mousseuse. Volupté; quand tu paraî́s je suis ivre de volupté.

ROSE sans épines. Ami, or amie sincèré. 
ROSIER églantier. Vous persuadez mon cour.

L'églantier est un arbrisseau très-commun dans nos bois et le long des haies, qui fleurit au printemps. Dans les Jeux Floraux, l'églantine d'or est le prix d'une pièce en prose pour exciter à l'étudede l'éloquence.

SAFran. N'abusez pas des plaisirs.

Le safran printanier fleurit très à bonne heure, quelquefois en hiver; c'est de l'espèce cultivée que vient celui que l'on emploie fréquemment en médecine: les anciens ont beaucoup vanté ses qualités, qui n'ont rien perdu de leur réputation chez les modernes; le principe éthéré qu'il renferme est extrêmement subtil, et agit de telle manière, que si l'on respire un air imprégné de ses parties ollorantes, il peut devenir fort dangereux : employé modérément, il excite à la gaieté, et porte à la folie ceux qui en abusent.

On l'a consacré à Cérès.

\section{SAINFOIN d'Espagne. Choisissez vos amis.}

Ce beau sainfoin fleurit en juin et juillet; il est cultivé avec grand soin par les jarliniers fleuristes, pour l'ornement des jardins; c'est un des meilleurs fourrages, mais à qui le voisinage des mauvaisus herbes est contraire:

SAlicalre à épis. Tous me dédaignez.

Il serait à désirer que l'on cultivât la șalicaire dans 
nos jardins, et sur-tout sur le bord des pièces d'eau, puisque, par ses beaux épis dont le port est élégant et les couleurs charmantes, elle offrirait une variété fort agréable; mais parce qu'elle est commune dans nos vallons humicles et sur le bord de nos ruisseaux, elle est dédaignée et on la cultive rarement.

\section{SAPIN, Elévation, grandeur d'ame.}

Le sapin est un très-bel arbre toujours vert, qui habite les hautes montagnes, où il forme de vastes forêts; il est très-commun en Suisse, et se plaît dàns les régions extrêmement élevées : il y vient d'une hauteur prodigieuse.

\section{SaUGE. Toute bonne.}

Toutes les parties des sauges répandent une odeur aromatique et pénétrante, qu'elles conservent même séchées; elles sont employées avec succès dans différentes maladies, et servent à la composition de liqueurs spiritueuses: l'une de ces espèces a été nommée toute bonne, à cause de ses excellentes propriétés; elles fleurissent dans la belle saison.

\section{SAULE. Vons plairez d̀ torıl áge.}

Le saule commun ou blanc est un habitant de nos prairies humides; on en voit aussi beaucnup au bord des eaux : tout le monde sait qu'il crôit encore avec vigueur lors mêne qu'il ne lui reste plus que l'écurce. 
SAULE pleureur. ITélancolie, chagrin, douleur.

C'est au bord d'un ruisseau solitaire, ou retiré au fond d'un bosquet sombre, que l'on aime à rencontrer la pâle verdure du saule pleureur. L'amant infortuné vient pleurer sous son ombrage chevelu; et après avoir payé le tribut de la douleur, croit entendre dans le doux murmure de ses feuilles agitées, des paroles de consolation; il ne quitte qu'avec chagrin ce lieu où ses peines lui semblaient être adoucies par la présence d'un tendre ami: la jeune bergère dont le cœur vient de s'ouvrir à l'amour, rêvera plus mollement à celui qui occupe toutes ses pensées; les émotions nouvelles qu'elle éprouve lui paraîtront senties et partagées par cet arbre cher aux ames tenilres: elle a choisi naturellement, et sans y penser, l'asile que lui offre son feuillage tristeet mélancolique; c'est là que l'image de son amant vient se présenter à son cœur ému, avec tout le charme que cause le premier soupir de l'amour. Auprès d'un tombeau, le saule pleureur paraît mêler ses regrets aux nôtres, et partager nos clouleurs; ses rameaux longs et flexibles, penchés doucement vers la terre, semblent pleurer avec nous.

SCABIEUSE, vulgairement FLEUR de veuve. Absence; vous m'abandonnez, vous me délaissez.

La scabieuse qui paraît dans les mois de juillet, août et septembre, nous a été apportée de l'lnde; depuis long-temps on la cultive dans nos jardins: sa 
couleur, qui est d'un pourpre brun, lui donne un aspect triste; ce qui lui a fait donner son nom vulgaire.

Sceau de Salomon. Voyez Muguet anguleux.

Sensitive. Voyez ACACIE pudique.

SERPOLET. Vojez THYM.

SII.ÉNÉ attrape-mouche. TYous m'avez trompé.

Le siléné cultivé est d'un aspect assez agréable pendant tout l'été, temps de sa floraison; son odleur attire les insectes sur sa tige garnie d'une substance visqueuse, qui les arrête et produit l'effet de la glu.

SOlEIL. Voyez HÉliaNTHE à grande flẹr.

Sorbier domestique, ou Cormper. Prudence.

Le sorbier est un très-bel arbre dont le bois est des plus durs; il croît très-lentement, et ne rapporte des fruits que dans un âge avancé : il est naturel à nos bois.

Soucr des jardins. Inquiétude, soupçons, jalousie.

Cultivés depuis long-temps dans nos jardins, les soucis y font un assez jo'i effet par le jaune éclatant de leur fleurs qui s'épanouirsent depuis le mois de juin jusqu'en septembre. Cette plante est d'une odeur forte et désagréable; son nom vient de solsequium, parce que ses fheurs se tourneat au soleil, 
Un souci d'argent est adjugé pour prix lle l'élégia dans les Jeux Floraux.

Souci pluviale. Précaution; vous' étes prévoyante.

Aux approches du mauvais temps, le souci pliviale semble prévoir l'orage, et ferme ses jolies fleurs d'une belle couleur pourpre en déhors et blanche erz dedans: on le cultive depuis long-temps en Europe, on il fleurit tout l'été.

SPIRÉE. Vouls régnez dans mon coour.

Le genre de spirées comprend un grand nombre d'espèces de plantes, toutes jolies et faciles à cultiver: une d'elles, la spirée filipenclule, a des feuilles très-découpées, et donne, au mois de mai, des bouquets de fleurs blanches, petites, mais extrêmement jolies, et de l'aspect le plus gracieux; une autre, appelée la reine des prés, à raison de sa besuté, fait paraître en juin et juillet des touffes de fleurs charmantes, blanches et nombreuses.

\section{Stramoine commune, Datura, Déguisement, arlifice.}

La stramoine est une plante d'une très-belle apparence, mais dont on doit se méfier comme d'un. poison dangereux; si on la froisse entre ses doigts, elle répand une odeur qui porte à la tête, et pourrait même occasionner des vertiges. 
SUREAU commun, HiÉBLe. Vous me consolez de. toules mes peines.

Peu de plantes sont aussi généralement répandues et jouissent d'une aussi grande réputation que le sureau dont les fleurs se montrent en juin : il est trèspeu de maux qu'il ne puisse guérir ou calmer; aussi le trouve-t-on placé autour des habitations; les champs en sont environnés.

Sycomore. Voyez ERABLE des montagnes.

SYRINGa odorant. Amour fralernel.

Les fleurs du syringa , charmant arbrisseau répandu dans toute l'Europe, paraissent à la fin de mai; elles sont blanches, et exhalent une odeur trèsforte, mais agréable: son nom générique philadelphus, qui signifie aimant son frère, vient d'un des Ptolémée, roi d'Egypte, auquel ce genre a été dédiè.

Tabac cultivé, Nicotiane, Petun, etc. Je surmonterai tous les obstacles.

Le tabac originaire de l'A mérique est répandu depuis deux siècles et demi dans les quatre parties du monde, où on le cultive, et où il donne, depuis juillet jusqu'en novembre, des fleurs assez belles en forme d'entonnoir, d'une couleur purpurine. Tout le monde sait que cette plante, tout inutile qu'elle peut être, est généralement en usage, malgxé qu'clle appartienne à une famille qui contient plu- 
sieurs poisons; on est encore à décider quel puissint attrait l'a fait rechercher et l'a rendue nécessaire, au point de faire souffrir celui qui ne peut satisfaire ce goutt, qui devient avec l'habitude un véritable besoin. $\mathrm{Il} \mathrm{a}$ eu, dit Bomare, ses détracteurs * et ses panégyristes. Amurat IV, empereur des " Turcs, un czar et un roi de Perse, en défendirent " l'usage à leurs sujets, sous peine de la vio ou " d'avoir le nez coupé. Jacques Stuart, roi d'Any gleterre, et Simon Paulli, ont fait un traité sur " le mauvais usage du tabac. On trouve une bulle * d'Urbain VIII, par laquelle il excommunie ceux " qui prennent du tabac dans les églises. Le père "Labat dit que le pelun fut comme une pomme de ») discorde, qui alluma une guerre très-vive entro 2 les savans.

\section{Taraspic. Voyez IBÉRIDE.,}

TAMMIER, sceau de Notre-Dame. Soyez mon appui,

Le tammier commun se trouve dans toute l'Europe, dans les bois humicles, le long les haies, ou i. entortille ses faibles tiges d'une manière agréable; if fleurit depuis le mois de mai jusqu'en août.

\section{TAGet, ou OEILET d'Inde. Vous avez quoique jeune la prívoyance de l’àge mûr.}

L'œillet d'Inde fait un assez joli effet dans nos parterres par la belie couleur de ses fleurs qui durent 
depuis l'été jusqu'à la fin de l'automne; son nom vient de Tagès, un des petits-fils de Jupiter, auquel on a dédié ce genre. Selon les poëtes, ce Tagès, encore enfant, enseignait aux Etruriens l'art de deviner.

Thym-Serporet. Emotion: en vous voyant je suis ému.

Le nom grec du thym signifie éreiller, émourant le sang. Cette plante aromatique se trouve en Europe, sur les collines, et dans les pâturages secs; ses fleurs qui paraissent en été, sont très-recherchées des abeilles.

THUYA, Rien ne pourra changer mon carur.

Les thuyas peuvent se placer dans les bosquets d'hiver, parce qu'ils ne perdent point leur verdure: ils ont beaucuup de ressemblance au cyprès; celui d'Occident ou du Canada fleurit au printemps.

On recommande aux jardiniers de ne point couper les branches inférieures de cet arbre, qui tombent d'elles-mêmes à mesure qu'il s'élève : les amputations faites aux arbres résineux leur sont très-nuisibles.

TILleUl. Vos bonnes qualités vous font aimer.

Le tilleul est un très-bel arbre d'Europe, d'un port noble et d'une verdure charmante; ses fleuro dont on fait un fréquent usage en médecine, répanclent au printemps une odeur très-agréable, er 
fournissent aux abeilles une abondante moisson : or le cultive pour en former des allées ou des massifs; ses rameaux flexibles se prêtent à toutes les formes, et en mariant leurs branches amoureuses, semblent nous irviter à jouir de leur ombrage.

TRÈFLE. M'est-il permis d'espérer le bonkeur?

Il y a beaucoup d'espèces de trèfles presque toutes naturelles à l'Europe; elles fleurissent en mai et juin, et forment un assez bon pâturage dans nos prairies. Les jeunes personnes s'amusent à chercher des trèfles à quatre feuilles, qu'elles regardent comme un signe de bonheur.

T'U BÉREUSE. Vous inspirez les plus tendres sentimens.

C'est de Perse que nous fut apportée la tubéreuse, très-belle plante dont la tige élancée se termine en un superbe épi de fleursblanches; l'odeur suave qu'elle exhale embaume l'air: c'est ordinairement en automne qu'elle s'épanouit; mais on peut, en la semant en divers temps, en avoir presque toute l'année.

Linnée lui a donné le nom grec polianthès, qui siunifie fleur digne de la ville.

\section{TULIPE, Magnificence.}

Tulipe vient de tulipan, nom que les Turcs ont donné à cette fleur à cause de sa ressemblance avec un turban: cette superbe plante est très-répandue dans nos parterres, et en fait un cles plus beaux. 
ornemens; il n'en est point dont les nuances soient aussi agréablement disposées. Les Turcs chez qui elle est très-commune, portent l'amour de ses fleurs jusqu'à célébrer tous les ans, dans le sérail du GrandSeigneur, une fête en l'honneur des tulipes.

\section{TULIPIER. Tous tardez à faire mon bonheur.}

C'est de l'Amérique que nous vient le tulipicr, très-bel arbre qui ne fournit des fleurs qu'à l'àge de quinze ou seize ans: sa feuille superbe a la forme d'une lyre antique; sa fleur qui ressemble à une tulipe, est d'un jaune tendre mêlé de vert, et d'une belle couleur aurore; elle paraît en juin et juillet.

\section{TUSSILAGE odorant, vulgairement Héliotrope d'hiver. Peut-être zon jour vous m'appré- -cierez mieux.}

L.e tussilage odorant est une plante très-intéressante, parce qu'elle fleurit clans l'hiver, et répand une odeur délicieuse; on ne la connaît que depuis peu de temps: il est étonnant que son odeur suave ne l'ait pas fait cultiver plutôt.

\section{Valérianne grecque. Voyez PolÉmoine bleue.}

\section{Valérianne rouge des jardins. Facilité.}

On cultive pour l'ornement des jardins la valérianne rouge, dont les fleurs se succèdent depuis le mois de mai jusqu'zux approches des gelées; elle croît 
sur les terrains rudes et pierreux, et méme dans les fentes des murailles.

VÉLAR des boutiques, vulgairement HERBE diz chantre. Ma faible voix peul célébrer vos charmes.

C'est ordinairement autour des villes et des villages, sur les vieux murs et parmi les décombres, dans toute l'Europe, que l'on trouve le vélar; ses feuilles s'emploient en décoction dans l'enrouement et l'extinction de voix; on en fait un sirop appelé sirop du chantre.

VERGE d'or. Rassurez mon ame afligée.

Les fleurs jaunes et nombreuses dle la verge d'or forment un assez joli effet dans nos parterres; elle ne fleurit que sur la fin de l'étẻ, quelquefois à l'entrée de l'hiver: son nom latin, solidago, vient do ce qu'on lui attribue la faculté de consolider les plaies.

VÉRONIQUE. Je pous offre mon cantr.

La véronique, jolie petite fleur bleue qui paraît dans la belle saison, le long des chemins, dans les haies, comprend beaucoup d'espèces, toutes trèsutiles en médecine, et dont plusieurs ont leur fruit en forme de cœur.

Le nom générique veronica fut, dit-on, celui d'une princesse à qui on dédia cette plante; son nom grec sira onike, veut dire vraie image. 
Verveine, vulgairement Herbe sacrée. Pureté de sentimens.

La verveine était fréquemment employée par les anciens dans les sacrifices de leur religion; elle servait à nétoyer les autels de Jupiter; les Romains en chassaient les mauvais esprits des maisons, et la portaient pendue au cou pour détruire les enchantemens.

VIGNE. Toresse de la passion.

La vigne, arbrisseau sarmenteux, était connue dans la plus haute antiquité; elle était en grand honneur chez les anciens, qui s'en couronnaient dans les fêtes appelées Bacchanales: on sait que les poëtes l'ont consacrée à Bacchus.

VIGNe vierge. Voyez MORELLE douce-amère.

VioletTe odorante. Modestie, timidité, amitié.

" L'humble et modeste violette qui aime l'ombre " et le frais, et qui semble se cacher pour augmen. " ter le plaisir de celui qui la cueille, a été célébrée "dans tous les temps par les poëtes; elle n'est pas "mcins chère aux amans: le doux parfum qu'elle 》 exhale, et le beau bleu dont sa corolle est tente, " en flattant également la vue et l'odorat, impri" ment à l'ame un sentiment de volupté dont on a "peine à se défendre: après la rose, c'est peut-être 
- "la fleur la plus recherchée des belles; elle dure » peu, mais elle est une des premières que le prin" temps fait éciore. " D. Noupeau Dict. d'Histoire naturelle.

Dans les Jeux Floraux, la violette était le prix d'ún poëme héroïque ou d'une pièce de vers sur l'amitié.

VIOLETTE-PENSÉE. Je pense à vous, pensez à moí. Vous seul occupez ma pensée.

La pensẻe fleurit toute l'année; l'élégance de ses fleurs, la vivacité, l'harmonie et le velouté de ses couleurs, la font remarquer de tout le monde. Qui ne connaît pas la pensée? Son nom seul la rendrait intéressante. Cette plante conserve la fraîcheur do ses nuances dans un livre ou un herbier.

Viotier. Vyez Giroflée des jardins.

VIORNE, boule-de-neige. Réfroidissement.

C'est au mois de mai que paraissent les fleurs belles et nombreuses de la boule-de-neige, qui font un très-joli effet, et contrastent agréablement par leur blancheur avec les autres fleurs le nos jardins; ses feuilles et ses baies employées en gargarisme sont très-rafraîchissantes.

VIPÉRINE vulgaire. SERPENTAYRE. Vos yeux font de cruelles blessures.

Le nom de vipérine a été donné à cette ṇlante, 
ex ce que ses semences ont la forme d'une tête de . vipère : son aspect est agréable; mais on ne doit pas la toucher, parce que ses tiges sont chargées cle poils qui causent des démangeaisons cuisantes: elle crốt par toute l'Europe, dans les bois, les champs, les terrains en friche, et sur le bord des chenins.

VolubILIs. Voyez IpOMÉA pourpré.

ZiZanie. Voyez IVRaIE. 


\section{B O Q Q E T D'AMOUR FILIAL.}

C'est aujourd'hui la veille d'un heureux jour pour nous, mon frère; tu vois que je veux parler de la fête de maman. Quel plaisir nous allons goûter en Iui donnant notre bouquet! tu sais avec quelle satisfaction elle le recevra. Descendons au jardin, et choisissons les fleurs les plus belles et les plus fraîches: commençons par cueillir ce joli muguet; c'est bien le retour du bonheur pour nous. Oh oui, ma sœur, tiens, coupe cette belle branche de géranium qui répand une si douce odeur! maman m'a dit suuvent que celte plante exprimait les plus beaux sentimens. Cette giroflée qui marque la simplicité de nos cœurs! cette jolie tige d'héliotrope! Oh! nous aimons bien maman plus que nous-nênes: ces immortelles lui diront que nous la chérirons toute la vie, ces 
beaux cillets ( 1 ) lui exprimeront notre amcur; et ces deux boutons de rose, c'est nous, mon frère; 6tons-en soigneusement les épines pour ne pas déchirer ses jolies mains: viens clans la prairie, mon bon Jules, nous y prendrons quelques joncs (2); tu sais bien ce que cela veut dire? Aussitôt dit, aussitôt fait ; ils attachent donc leur bouquet avec des joncs, le posent sur un lit de mousses ( 3 ), après l'avoir enveloppé de feuilles vertes (i) : Ah! ma sœur, nous avons oublié la fleur favorite de maman, la pensée: aussi, tu me presses tant! Vîte ils clétachent le bouquet, et y joignent les plus belles pensées; ensuite il enlacent leurs petits bras, cts'en vont tout fiers porter leur offrande. Heureuse mère! quels délicieux sertimens tu vas éprouver!!!

(1) Amour pur. (2) Docilité. (3) Sensations douces, sensations heureuses. (4) Espérance. 


\section{BOUQUET D'AMOUR.}

Va , bouquet chéri, porte à celle que j'aime l'image de mes sentimens, dis-lui tout ce qu'un cœur bien épris peut sentir de plus tendre! Puissai-je t'animer de mes feux! Puisse ta muette éloquence lui peindre mon ardeur!!! Beaux cillets (I), brillez-y cle toutes parts; tendre héliotrope (2), fais-lui connaître l'excès de mon amour! le tournesol (3) Jui apprendra que je ne vois et ne desire qu'elle; la branche de fusain (4), que son image est pour jamais tracée dans mon cœur: le myrte (5), les immortelles (6), le lierre anoureux (7), s'uniront pour lui prouver la flamme la plus constante et la plus pure، Aimable langage ! ah, permets-moi d'emprunter tes expressions touchantes! elles seules conviennent à mon amour.

(1) Amour pur. (2) Je vous aime plus que moimême. (3) Mes yeux ne voyent que vous. (4) Votre image est tracée dans mon cceur. (5) Amour. (6) Amour. sans fin. (7) Je meurs ou je m'attache. 


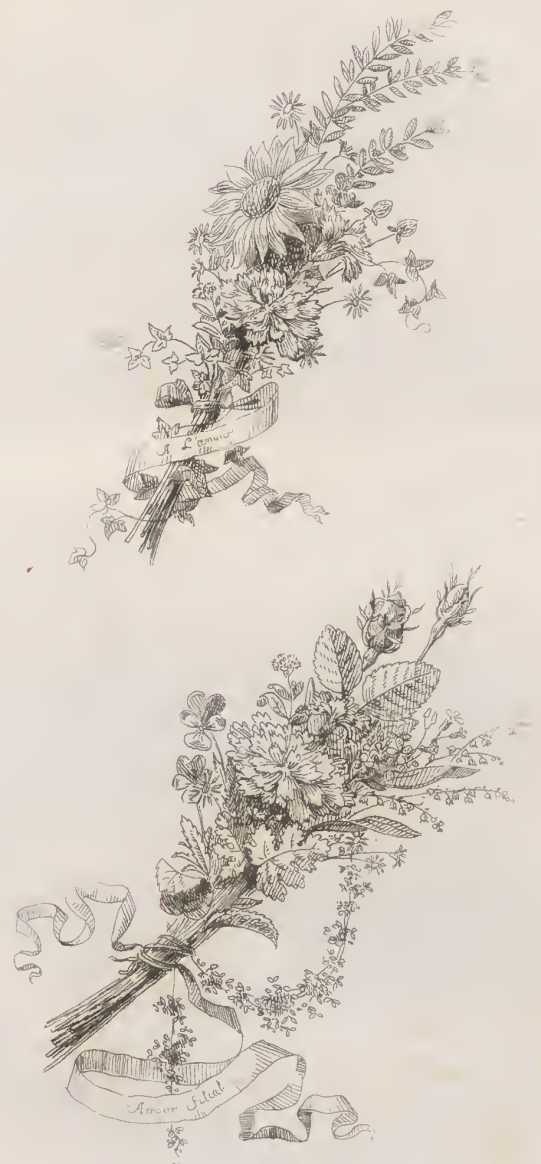




\section{L'INCERTITUDE}

\section{ET L'ÉCLAIRCISSEMENT.}

C'est en vain que je cherche les fleurs que j'aime; mon parterre ne m'offre plus que l'inconstante énothère (1), la fragile éphémérine (2), et le fruit do la piquante épinevinetze (3). Qu'est devenu le temps où je rencontrais le doux lilas (4), et qque, me reposant sur de faibles mousses (5), je remarqquais le vert tendre de l'orobe printanier (6), et les prairies émaillées par le blanc perce-neige (7)? Ainsi une jeune et sensible amante se plaignait de son amant, et le croyant infidèle, regrettait le temps heureux qui vit naître leurs premières émotions. Pour lui faire connaître sa peine, elle cueille quelques branches

(1) Inconslance. (2) Bonheur d'un instant. (3) Dous me fuyez. (4) Première émotion d'amour. (5) Sensations douces, sensations Tieureuses. (6) Besoin d'aimer. (7) Premier soupir d'amour: 
d'épinevinette (8), du géranium triste (9), des soucis (10), et une tige d'if (11); elle y joint la fleur de l'hélènie (12) et la sombre scabieuse (13), en forme un bouquet, l'attache de lierre (14), et le dépose sur cles balsamines (15) et des feuilles de fougère (16). Elle attend la réponse avec une impatience extrême : mais à quelle joie ne se livre-t-elle pas! Une erreur avait occasionné ses soupçons : elle reçoit en échange une tige de dauphinelle ( 17 ), une branche de châtaignier (18), un tournesol (19), auxquelles s'unissaient avec grâce des immortelles (20) et des pensées (21); la verveine sacrée (22), en lui exprimant ia tendresse la plus pure, se liait à la consolante marjolaine (23). Ce bouquet était couronné par une branche de myrte (24).

(8) Vous me fuyez. (9) Mélancolie. (10) Inquiétude, souppons. (11) Tristesse. (12) Pleurs. (13) Vous m'a. bandonuez. (14) Je meurs où je m'allache. (15) Impa. tience. (16) Incertitude. (17) Lisez dans mon cœur. (18) Connaissez-rnoi mieux, rendez-moi justice. (19) Mes yeux ne poyent que pous. (20) Amour sans fin. (21) Vous seule occupez uua pensée. (22) Purelé de sentimens. (23) Séchez pos larnues. (2/4) Toul amour. 


\section{BOUQUET D'HYMEN.}

Amour, viens à mon aide! composons un bouquet digne de mon époux, et des sentimerss qu'il m’inspire. La rose sans épines ( 1 ), jointe à la tendre pervenche (2), doit y prendre la première place; unissons le chevrefeuille (3) à la fleur de grenade (4); mêlons-y le myrte (5) et l'immortelle (6); que l'héliotrope (7) s'y distingue entre toutes les autres fleurs, à còté de l'éclatant tournesol (8); que la gesse odo. rante (9) s'enlace aux brillantes lychnides (10) et à la menthe des jardins ( 11 ) : écartons-en avec soin la froide ibéride (12) et le cruel souci (13). Amour me dit à l'oreille d'y placer une innocente lauréole (14),

(1) Amie sincère. (2) Amitié de toute la vie. (3) Liens d'amour. (4) Union, concorde. (5) Amour. (6) Amour sans fin. (7) Je pous aime plus que moinuême. (8) Mles yeux ne voyent que vous. (9) Plaisir délicat. (10) Fidélité ḋ toute épreupe. (11) Vertu, (12) Indifférence. (13) Jalousie. (14) Désir de plaire. 
enchaînée par une guirlande de mogori ( 15 ); i'y ajouterai quelques fleurs de myosotis (16), unies àla simple pensée (17); je l'envelopperai de buis (18), et le déposerai dans une corbeille formée d'ipoméa (19); je le prierai d'y ajouter, en le recevant, une jolie branche d'alizier (20), et du géranium odorant (2I).

(15) Parure. (16) Ne m'oubliez pas. (17) Vous seul occupez ma pensée. (18) Solidité. (19) Je m’attache à 20us. (20) Accord. (21) Estime, fidélité conjugale. 


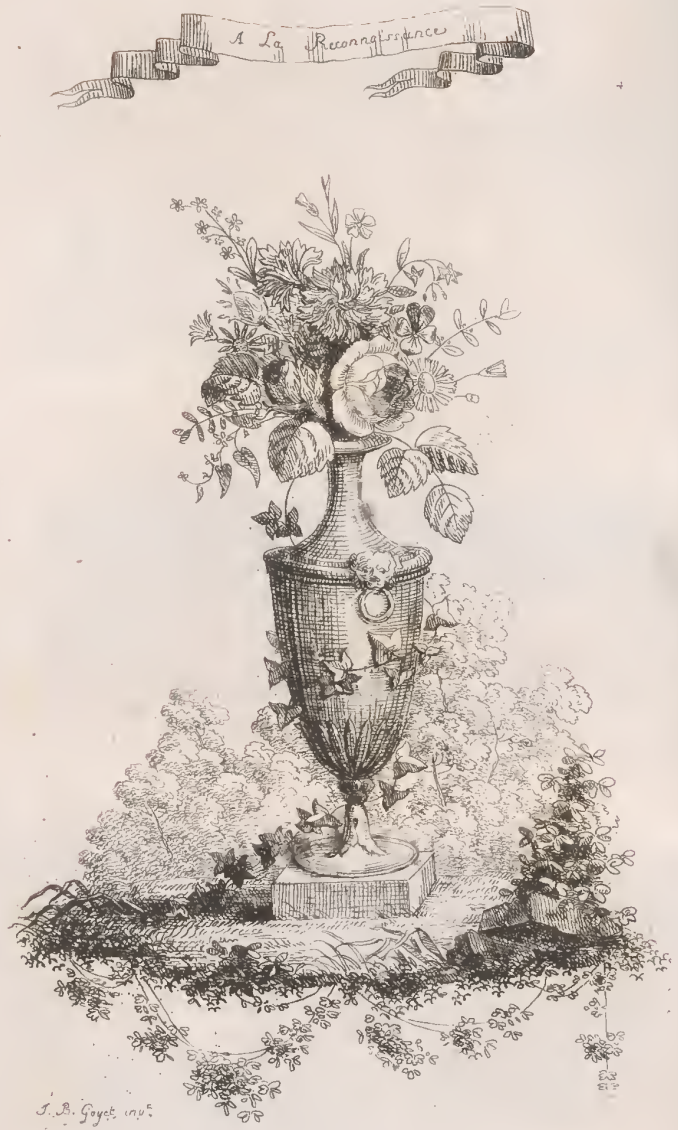




\section{BOUQUET}

\section{A LA RECONNAISSANCE.}

Ce bouquet pourrait être composé ainsi : une branche de figuier, unie à la verveine pour marquer la reconnaissance et la pureté des sentimens; une tige de fleur de lin annoncerait que le cœur sent tout ce qu'il doit; du buis, la solidité et la durée de l'attachement; le géranium peindrait l'estime parfaite; de la camomille romaine, pour désigner que l'on désire se rendre digne des services que l'on a reçus; une branche de vigne-vierge ou clouce-amère, pour la sincérité de l'ame; les petites fleurs de la myosotis exprimeraient la crainte d'être oublié; des fleurs de tamier on sceau de Notre-Dame réclameraient de nouveau la protection; des feuilles d'ormeau témoigneraient la considération et le respect; et enfin, des immortelles et des pensées, clont on connaît la signification : mais, pour embellir ce bouquet, on pourrait y ajouter des cillets et des roses. 


\section{L'A N N IV ER SAIRE, OU LE TOMBEAU*.}

Le soleil, d'un jaune pâle, commençait à paraître sur l'horizon, et dessinait à mes yeux les restes d'un temple; ouvrage des hommes, il a dû périr comme eux. Des portiques dont les touffes de valériane, les giroflées et la joubarbe aux épis rougeâtres permettaient à peine d'apercevoir la richesse des or memens; des statues brisées, des colonnes renversées laissant des corniches suspendues dans les airs; des monceaux de pierres entassées, annonçaient son antique splendeur: il a brillé.... le chapiteau qui s'élevait orgueilleusement, paré de la feuille d'acanthe, est maintenant au niveau de la base.

Un pâtre arrive empressé de faire paître à ses chèvres l'herbe chargée de rosée ; le troupeau grimpant bientôt est dispersé : les unes vont brouter impunément les aconits et la ciguë; les autres, en bondissant, atteignent le sommet des ruines; elles $y$ trouvent des plantes placées par la sagesse de la

* Par J.B. G...t. 
nature, qui utilise même la destruction. Les petits chevreaux arrêtent par leurs cris leurs mères trop agiles qui, pleines de sollicitude, les attendent, et semblent encourager leur incertizude et leur timidité.

Le berger sort de sa panetière un hautbois; il s'appuie contre le fat d'une colonne; la nature a été son maître, et il prélude des airs aussi simples que lui. Je n'avais encore entendu que le chant de quelques oiseaux; mais le signal est donné; ils se réunissent en troupes nombreuses, et mille concerts retentissent : de temps en temps ils s'interrompent pour laisser chanter seule la tendre Philoméle, mais ils recommencent avec plus d'ardeur pour s'arrêter de nouveau et recommencer encore. Tout s'anime, tout respire la vie et l'amour; les petits oiseaux, par leurs cris aigus, demandent la becquée qu'une mère prévoyante leur apporte déjà.

Bientôt le soleil colure les montagnes cle ses rayons dorés; il pompe avec arleur la rosée qui est allée atteindre la modeste violette sous sa feuille mystérieuse, et qui, glissant sur la clochette du muguet, est tombée en perles sur son beau feuillage, et semble en imiter la fleur. Ses rayons brûlans me forcent de chercher un asile à l'ombre d'un vieux chêne tapissé de lierre; l'ame encore émue, je veux tracer un tableau si imposant: je préparais mes crayons, j'allais commencer mon ouvrage, lorsque, dans un sentier non loin de moi, paraît un jeune enfant: il porte sur ses deux petits bras des couronnes de fleurs sur 
lesquelles ses yeux se tournent alternativement, ce qui rend sa marche incertaine. Cet enfant me parait beau; de longs cheveux châtains tombent en boucles sur ses épaules. Une jeune femme le suit; une sombre mélancolie est répandue sur sa figure qui respire la modestie; elle porte une corbeille remplie de fleurs. Un vieillard s'appuie sur son bras; il a la tête penchée sur la poitrine; il hésite en marchant, ce qui me le fait juger aveugle. Tous gardent le plus profond silence, et le chien qui les précède semble partager la tristesse de ses maîtres. Ils ne m'aperçoivent pas; et toujours à la même place, je les suis des yeux; mais ils entrent dans un épais taillis.

Je ne doute pas un instant de l'intention de cette famille intéressante; c'est l'anniversaire d'un jour malheureux qu'elle va célébrer. L'intérêt et non la curiosité me fait désirer d'être témoin de cette scène touchante; mais la crainte d'être indiscret me retient: cependant je me lève, et je suis lentement le même chemin. Je pénètre dans le taillis; plusieurs sentiers s'offrent à ma vue; des fleurs effeuillées m'indiquent celui que je dois suivre. Je marche avec précaution pendant quelques instans, moccupant à cueillir des petites fleurs de myosotis pour retarder ma marche et leur donner le temps d'arriver; enfin, une voix frappe mon oreille, c'est celle du vieillard.

« Depuis cinq ans nous t'avons perdu, mon cher " fils, et cette perte nous paraît aussi récente que si. 
* nous venions de l'éprouver. Mes yeux étaient déjà " privés de la lumière, lorsque la mort qui ne res» pecte ni les vertus ni les talens, t'enleva à la fleur " de l'àge. La cruelle! c'était moi qu'elle devait » frapper.... Je ne pouvais te voir; mais il me semble » encore recevoir tes derniers embrassemens: je "sens tes membres glacés; j'entends encore ces " mots, adieu mes amis, expirer sur tes lèvres; je "les couvris des miennes; je voulais retenir cette » ame prête à s'envoler: tu n'étais déjà plus.... Mes » regrets égalent l'amour et le respect que tu avais » pour ton père.... Oh! mon Dieu, tu as eu pitié de " moi, et je te cois des actions de grầces de m'avoir * Clonné un petit-fils qui sera le soutien de sa mal" heureuse mère.

"Nous élevâmes ce monument de notre dou"leur; tous les ans i'y viendrai déposer des fleurs " arrosées de mes larmes, jusqu'au temps où j'irai " te rejoindre $"$.

Les pleurs et les gémissemens qui succédèrent à un instant de silence, me laissèrent a peine entendre ces mots:

" J'avais un époux; il réunissait la beauté aux 》 qualités du cœur; on admirait ses talens... Main" tenant, une terre froide et humide couvre une

" tête si chère.... L'amour avait furmé nos liens, " tout semblait assurer notre félicité : je n'étais plus 》orpheline; je commençais à oublier les malheurs " de mon enfance : je n’avais rien à désirer; je cou- 
* lais des jours heureux : je jouissais doublement du " bonheur de mon époux et du mien, j'allais être " bientôt mère..... Mais, cher époux, tu ne l'as pas "vu, ce fils; tu n'as pas reçu ses caresses! lor squ'il " vit le jour, tu venais de le perdre.... Je lui ai " déjà appris à t’aimer, à te regretter. Ah! si je " tiens à une vie qui ne peut être heureuse sans " toi , c'est pour ce cher fils..... Viens, mon ami, " joins tes petites mains, et dis avec moi : "Mon " père! " et le petit enfant répète : "Mon père! toi » que je ne connus que par les regrets d'une tendre " mère, dlu haut de la céleste demeure où sans " doute tu habites, reille sur ton fils, dirige ses " pas dans le sentier de l'honneur, et..... "

Ici le bruit des feuilles agitées par le vent, et les plaintes d'une tourterelle qui avait perdu son bienaimé, tn'empêchèrent d'en entendre davantage.

Les sons de l'airain, qui venaient de frapper les airs, s'étaient prolongés jusqu'à nous: “ ma fille», dit le vieillard, " entends-tu l'annonce de la pre" mière prière? Susperıds tes larmes; viens dans le "temple du Tout-Puissant invoquer sa protection " pour notre cher enfant..... Adieu cher époux! » adieu mon fils! adieu mon père! " s'écrièrent les trois voix à-la-fois.

Je m'enfonçai lans le bois; bientôt j'entendis leurs pas, et je reçus la visite du chien qui vint me faire des caresses.

J'avais les yeux inondés de larmes; et moi aussi, 
m'écriai-je, j'ai perdu! ..... et les deux bras croisés sur la poitrine, je m'acheminai du côté du tombeau. Un treillage, à hautcur d'appui, en défendait l'entrée; $j$ 'allais pénétrer dans l'enceinte : mais un saint respect me retint, et je me contentai de parcourir l'extérieur.

Un saule pleureur ( 1 ) couvrait presque entièrement de ses longs rameaux une tombe de gazon, et laissait à peine apercevoir une croix de bois d'acacia (2); elle était entourée d'ifs (3), de cyprès $(4)$, que réunissaient des guirlandes de lierre (5), auxquelles étaient suspendues des couronnes formées de buis (6), d'immortelles (7) et de pensées ( 8 ). Le terrain était jonché de scabieuses (9), dont l'habit de deuil contrastait avec les roses (10) que l'on venait d'effeuiller. L'asphodelle (11) a fleurs jaunes, les pensées, les immortelles, et l'alonide à fleurs purpurines (12), se mêlaient au buis qui bordait le tombeau. Un ruisseau qui d'espace en espace formait des cascades, serpentait autour; il unissait

(1) Mélancolie, chagrin, douleur, (2) Sagesse. (3) Tristesse. (4) Regrets, désespoir, mort. (5) Je meurs où je m'allache. (6) Solidité, durée. (7) Toujours, éternité. (8) Vous seul occupez ma pensée. (9) Absence, vous m'abandonnez. (10) Amie sincère. (11) Mes regrets vous suivent au tombeau. (12) Souvenir tendre el douloureux, souvenir ineffaçable. 


\section{IO6 L'ANNIVERSAIRE, OU LE TOMBEAU.}

ses murmures au bruit de la féuille tremblante du peuplier (13), et semblait imiter les gémissemens que je venais d'entendre. Cet asile, où les rayons du soleil ne pouvaíent pénétrer, inspirait la vénération et la plus sombre mélancolie: je ne le quittai qu'avec peine; et, l'imagination errante, sans pouvoir fixer mes idées, je parcourus encore quelque temps la campagne,

(13) Plaintes, murmures. 


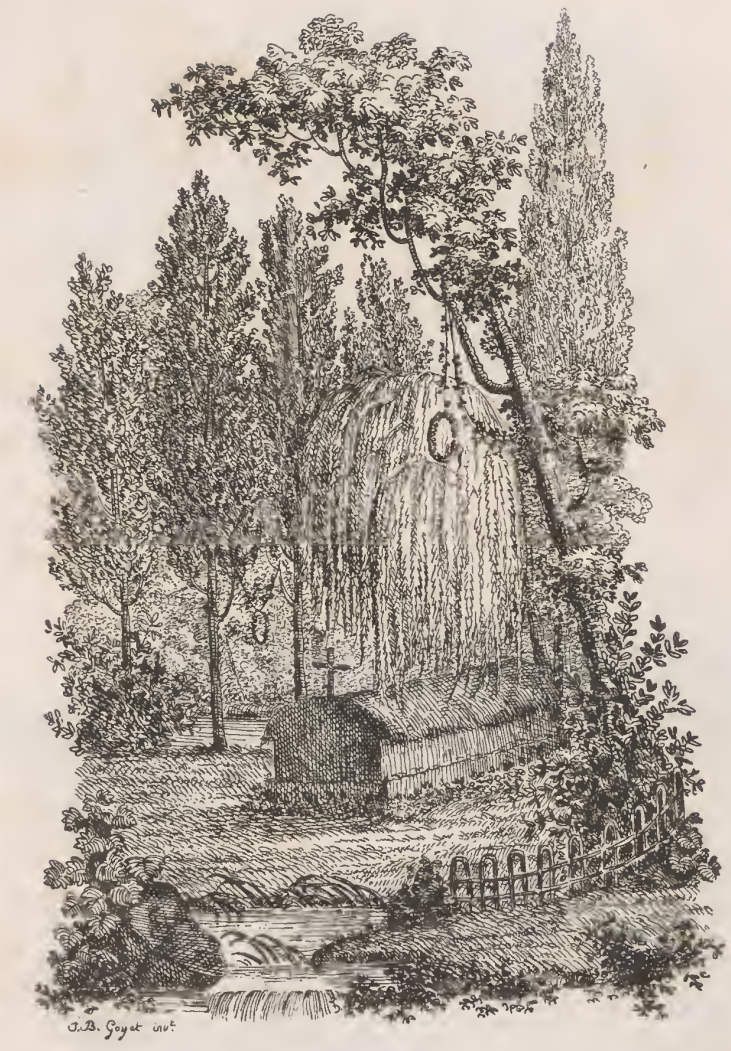




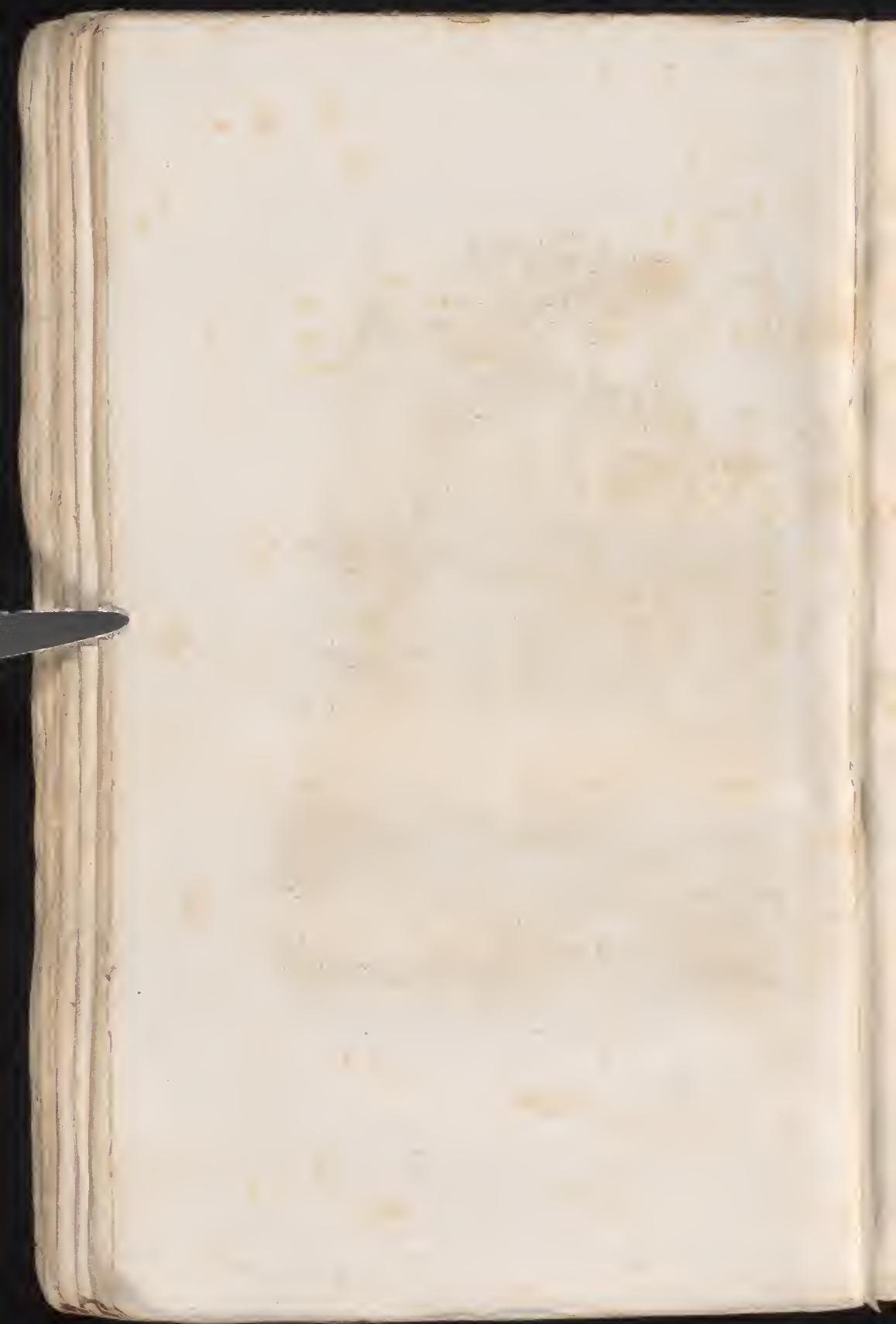




\section{MAN IÈ RE}

\section{DE GROUPER LES FLEURS.}

La nature si variée dans ses ouvrages offre un nombre infini d'objets à notre admiration; mais, de toutes ses productions, les fleurs sont celles qui nous charment le plus agréablement. Maintenant nous ne les regardons plus comme entièrement inanimées; l'une fuit la main indiscrète qui veut la toucher, l'autre aussi pudique célèbre son hymen au fond des eaux, d'autres enfin recherchent l'éclat du jour, et semblent sommeiller lorsqu'il les abandonne. Nous avons un plaisir infini à les voir; mais elles offrent à l'artiste qui les étudie, mille charmes de plus : et si des lois sont dictées par l'art à celui qui les peint, pourinuoi ne pas recourir aux mêmes règles pour les disposer avec grâce dans une corbeille qui doit être offerte, ou dans un vase destiné à l'ornement d'un. salon, que les fleurs soient artificielles, ou qu'on ait eu le plaisir de les cueillir?

Si l'on veut grouper des fleurs, c'est au centre que l'on doit placer les-plus belles et les plus grandes, puis les moyennes, ainsi de suite jusqu'aux plus petites qui doivent être aux extrémités : cependant, 
pour lier agréablement le tout ensemble, il faut avoir soin de glisser de petites fleurs entre les grandes et les moyennes, et de bien opposer les couleurs, telles que le pourpre, le violet, le lilas et le bieu clair, près du jaune, si c'est la couleur des principales fleurs.

Le jaune tendre, le couleur de chair, le bleu et le blanc, près du rouge.

Avec le violet: le rose, l'orangé, le jaune tendre et le blanc feront un bon effet.

Avec le bleu, il faut choisir le pourpre, l'orangé, le jaune tendre et le blanc.

Il faut éviter de placer près l'une de l'autre deux couleurs principales, comme le jaune foncé, le carmin et le bleu.

On remarquera que le vert foncé fait bien près des couleurs claires, et le vert clair près des couleurs sombres.

Dans un jeur anniversaire où l'on se plaît à payer un tribut d'amour à la nature, à l'amitié, si l'on veut orner de guirlandes de fleurs un appartement, on s'attachera à donner aux festons une forme gracieuse. Il doit être renflé dans le milieu, et aller en diminuant jusqu'aux extrémités: on placera, comme pour les bouquets, les Aleurs les plus belles par leur grandeur et leur couleur, au centre; ensuite, celles de moindre dimension, comme je l'ai déjà indiqué. On mettra à côté l'une de l'autre les couleurs qui, malgré leur opposition, soient amies, en se servant 
de fleurs pour nuancer la guirlande, comme si c'était des couleurs disposées sur une palette; de cette manière, les fleurs moins belles serviront à faire valoir la beauté des autres. Les fleurs simples se placent de préférence aux extrémités; et le bon goût qui indiquera que les fleurs panachées doivent être placées à côté de celles de couleurs unies, suppléera Eout ce qui mánque à cet article que la briéveté de louvrage ne me permet pas d'étendre davantage. 


\section{ALLÉGORIE \\ DES COULEURS.}

Les peintres comptent trois couleurs capitales ou primitives, qui sont: le rouge, le jaune et le bleu; le blanc est la lumière, le noir l'absence de la lunière. Les couleurs secondaires sont celles qui se forment du mélange de deux couleurs franches; tels sont le pourpre, l'orangé, le vert, le violet, le gris cendré, le gris brun, etc. Le vert se compose donc de jaune et de bleu, le violet de rouge et de bleu, etc. Ces couleurs produisent ensuite un nombre considérable de teintes ou nuances, que l'on porte jusqu'à huit cent dix-neuf; $j$ 'ai choisi les principales couleurs pour en donner le symbole.

\section{LE BLANC signifie Bonne-foi, candeur, pureté, innocence.}

Chez les Egyptiens, les Grecs et les Romains, les prêtres étaient vêtus de blanc; la couleur blanche était aussi un signe de joie, et les anciens s'en paraient dans les festins : cependant les femmes 
grecques et romaines qui avaient porté le deuil en noir comme les hommes, le portèrent en blanc sous les Empereurs. Ceux qui briguaient la magistrature, avaient des toges blanches, d'où leur est venu le nom de candidats : cette couleur a toujours été le symbole de la pureté, de la bonne-foi et de la candeur.

\section{LE Rovge. Pudeur, amour, ardeur.}

Le flammeum, voile que portait ordinairement la Flaminique Diale, prêtresse qui présidart aux mariages, était de couleur rouge par analogie au coloris de la pudeur : cette prêtresse ne pouvait se séparer de son mari par le dirorce; c'est pourquoi on couvrait de son voile les jeunes épousées le jour de leur mariage, pour en prendre un bon augure.

LE JA UNE signifiait chez les anciens gloire, splendeur. Il signifie chez les modernes infidétilé.

Les artistes ont fait de la couleur jaune, qui est celle du soleil, l'emblême de la splendeur et de la gloire. La blonde Cérès était représentée arec une draperie jaune, parce que cette couleur est celle de la moisson. Homère donne un voile jaune à l'aurore.

LE Bleu. Purelé de sentimens, élévation d'ame, sagesse, piété.

Cette couleur est celle du ciel; Junon qui désigne 
1'air, était vểtue de bleu céleste: on donne aussi a Minerve un manteau bleu.

LE Norr. Tristesse, deuit, mort.

Cette couleur qui est celle des ténèbres, a totijours été prise pour l'emblême du deuil et de la mort.

\section{Le Pourpre. Puissance suprếme.}

Jupiter était.représentẻ vêtu d'une draperie rouge pourpre; c'était la couleur des manteaux des Empereurs romains.

\section{LE ROSE. Jeunesse, amour, tendresse.}

Le rose est la couleur la plus tendre et la plus gaie; sa fraicheur convient à Hébé, déesse de la jeunesse.

LE VERT. Espérance.

De tout temps le vert a été considéré comme le symbole de l'espérance, sans doute parce que la verdure nous annonce les beaux jours, et que les feuilles précèdent les fruits. Le vert célaclon ou vert d'eau était consacré à Neptune; les Néréicles étaient représentées avec des draperies cle cette couleur, qui était aussi celle des bandelettes des victimes offertes aux dieux marins.

Dans un bas -relief antique, nn a figuré l'Espérance debout et couronnée de fleurs, ayant dans la main gauche des pavots, et s'appuyant de la Aroite sur une colonne; on a placé devant elle ane 
ruche d'où sortent des épis et des fieurs: par Ics épis on a désigné l'espérance des biens, celle des plaisirs par les fleurs, et l'oubli des peines par un pavot.

\section{Le Lilas. Amour pur.}

Je donne cette signification à la couleur lilas, parce qu'elle se compose de rose qui veut dire tendresse, et de bleu qui désigne la pureté.

LE Vrolet. Puissance célesle.

Le rouge et le bleu composent le violet; je prends ici le rouge pour la puissance, et le bleu comme essence divine.

L'Orangé. Amour de la gloire.

Cette couleur se compose de ronge et cle jaune. Je donne au rouge l'emblême de l'ardeur, de l'amour, et au jaune celle de la gloire. L'orangé signi. fierait inconstunce, en prenant le rouge pour amour, et le jaune pour infidélité.

LE GRis. Douleur tempérée, mélancolie.

Le gris est un mélange de blanc et de noir; la tristesse désignée par le noir, est modérée par le blanc qui est l'emblême de la jnie.

LE BRUN FONCÉ. Douleur profonde.

Le brun foncé était appelè par les Romains couleur noire. 
LE FeUILle MORTE, Tieillesse, destruction.

L'image de la destruction et de la mort ne peut être mieux peinte que par la feuille morte.

L'Amaranthe, Constance, immortalité.

En grec, amaranthe signifie qui ne se.flétrit point; c'est pourquoi je dorne à cette couleur l'emblếme de la durée.

UN RUBAN nuancé de plusieurs couleurs, signifie éloquence, persuasion, raccommodement.

Une étoffe nuancée de plusieurs couleurs, imite l'arc-en-ciel, dont les poëtes ont fait Iris, messagère des dieux.

UN RUBAN tramé de deux nuances, faisant couleur changeante, signifie légèreté, inconséquencs.

La signification que je donne à cette cuuleur, s'explique d'elle-même. 


$\begin{array}{ll}\text { Abondance. } & \text { Epi de froment. } \\ \text { Absence. } & \text { Scabieuse. } \\ \text { Accord. } & \text { Alizier. } \\ \text { Adresse. } & \text { Ophrise araignée. } \\ \text { Aimons-nous. } & \text { Primevére. } \\ \text { A la plus belle. } & \text { Pommier. } \\ \text { Amabilité. } & \text { Rose de mai. } \\ \text { Ami ou amie sincère. } & \text { Rose sans épines. } \\ \text { Amitié. } & \text { Violelte odorante. } \\ \text { Amitié de toute la vie. } & \text { Peroenche. } \\ \text { Amitié ou amour sans tin. } & \text { Immortelles. } \\ \text { Amertume. } & \text { Chicorée sauvage. } \\ \text { Amour. } & \text { IIyrle. } \\ \text { Amour caché. } & \text { Clandestine. } \\ \text { Amour des beaux-arts. } & \text { Acanlhe branc-zrsine: } \\ \text { Amour filial. } & \text { Géranium. } \\ \text { Amour fraternel. } & \text { Syringa. } \\ \text { Amour maternel. } & \text { Mauve grande. } \\ \text { Amour paternel. } & \text { Eupatoire. } \\ \text { Amour pur. } & \text { Eillet des jardins. } \\ \text { Annonce. } & \text { Galantine perce-neige: }\end{array}$


Ardeur.

Gouet commun.

Arrière-pensée.

Aster à grande fleur.

Artifice.

Stramoine datura.

Audace:

MTélèze.

Beauté, bonté.

Oranger, fruit.

Beauté brillante et passagère.

Beauté capricieuse.

Rose des quatre saisons:

Beauté froile.

Beauté innocente.

Rose musquée.

Beauté parfaite.

Hortense du Japon.

Rose blanche.

Beauté sans bonté.

Rose à cent feuilles.

Morelle cerisetle.

Beauté toujours nouvelle. Ketmie des jardins.

Besuin d'aimer.

Orobe printanier.

Bonheur d'un instant. Fiphémérine de Virginie.

Bon naturel.

Brillant.

Calme.

Calme de l'ame.

Calmez-vous.

Candeur.

Caresses.

Chagrin.

Molène, Bouillon-blanc.

Renoncule des jardins.

Alysse des rochers.

Pavot rouge ou coquelicot.

Phylolacca.

Oranger, fleur.

Tpoméa pourpré.

Saule pleureur.

Chaines d'amitié ou d'amour.

Chasteté.

Guirlandes de fleurs.

Choisissez vos amis.

Choix.

Gatilier commun.

Sainfoin d" Espagine.

Pommier.

Cour qui ignore l'amour. Rose en bouton. 
Colère.

Concorde.

Connaissez-moi mieux.

Considération.

Consolation.

Constance.

Constance dans l'adversité.

Coquetterie.

Critique:

Croyance.

Défendez-moi.

Dèguisement.

Délicatesse.

Désespoir.

Désir de plaire.

Deuil.

Discrétion.

Distinction.

Docilité.

Douceur extrême.

Douceur inaltérable.

Douleur.

Doux espoir.

Doux liens.

Durée.

Eclaircissement.

Eclairez-moi.

Eclat.
Momordique piquante.

Grenadier.

Châtaignier.

Orme ou ormeau.

Hellébore à fleur rose:

Amaranthe.

Palmier.

tiseron belle-de-jour.

Renoncule âcre.

Grenadille bleue.

Houx commun.

Stramoine commune.

Gesse odoranle.

Cyprès.

Lauréole, bois-gentil.

Cyprès.

IInguet anguleux.

Orme ou ormeau.

Jonc des champs.

Guimaupe.

Amandier communt.'

Saule pleureur.

Aubépine.

Cameline cultivée.

Buis.

Jonc épars.

Id.

Renoncule des jardins. 
Elégance.

Elévation.

Eloquence.

Embellissement.

Emotion.

Emportement.

Enchaînement.

Energie.

Enfantillage.

Entêtement.

Entrave.

Envie.

En vous voyant jo stis ému.

Erreur.

Espérance.

Estime.

Eternité.

Etourderie.

Extrême sensibilité.

Facilité.

Faiblesse.

Fatuité.

Faux-amour.

Feu d'amour.
Aster ou reine-marguerite, Sapin.

Iris bulbeuse.

Charme.

Thim, serpolet.

Momordique piquante.

Tiseron.

Bourrache.

QEillel mignonette.

Cocretle des prés.

Bugrane.

Ronces noires.

Thim, serpolet.

Noisetier.

Feuilles veries.

Géranium.

Immortelles.

Pissenlit.

Acacie pudique.

$V$ alériane rouge cies jardins. Adoxa musqué.

Nareisse des poëles.

Id.

Capucine.

Fidélité z toute épreuve. Iychnide de Calcédointe. Fidélité conjugale.

Fiel. Géranium.

Fumeterre commune.

Fierté.
Couronne impériale. 
Flatterie.

Foi.

Folie.

Force.

Force morale.

Franchise.

Frivulité.

Froileur.

Gaieté.

Galanterie.

Garantie.

Générosité.

Génie.

Gentillesse.

Gloire.

Gràce.

Grandeur.

Grandeur d'ame.

Guerre,

Guérison.

Guérissez-moi.

Harmonie.

Heureuะ présage.

IIsspitalité.

Humanité.

Imnortalité.

Impatience.

Inportunité.
Campanule miroir de Vénus.

Grenadille bleue.

Ancolie.

Aneth.

Chêne.

Morelle douce-amère. Brize tremblante.

Nénuphar.

Brise tremblante.

Id.

Nerprun.

Baguenaudier.

Platane.

Lauréole bois-gentil.

Laurier franc.

Butome à ombelle.

Zis blane.

Sapin.

Polémoine bleue.

Achillée millefenille.

Id.

Erable de montagne.

Galantine perce-neige.

Figuier.

Gratiole officinale.

Ambroisie.

Balsamine.

Bardane. 
Imprudence.

Incertitude.

Inconséquence.

Inconstance.

Indépendance.

Indifférence.

Indiscrétion.

Ingratitude.

Injustice.

Inquiétude.
Amandier satiné.

Fougère.

Pissenlit.

Enothère à grandes fleurs, Cerisier.

Ibéride, vulgairement taraspic.

Ophrise-mouche, roseani: plumenx.

Renoncule scélérate.

Ronces noires.

Souci des jardins.

Innocente victime de la jalousie.

Anémone.

Ivresse de la passion. Vigne.

J'ai perdu le repos. Etuphorbe réveil-matin.

Jalousie.

Je brûle.

Ciste, souci des jardins.

Cactier-raquetle.

Je cherche la solitude.

Je fuis, je redoute

l'amour.

J'éloignerai de vous les méchans.

Bruyere commune.

Nictage belle-de-nuit.

Je m'attache à vous.

Je me rendrai digne de vos soins.

Absinthe citronnelle.

Ipoméa jasmin ronge.

Camomille romaine.

Je meurs où je m'attache. Lierre.

Je ne puis vous quitter. Iychnide compagnon. Je ne vous survivrai pas. Murier noir. 
Je pense à vous.

Violette pensée.

Je sais apprécier vos ta-

lens.

Genêt d'Espagne.

Je sens tous vos bienfaits. $L i$ in.

Je serai docile.

Jonc des champs.

Je suis piqué.

Orlie,

Je suis votre meilleur ami. Cynoglosse prinlanière.

Je surmonterai tous les

obstacles.

Tabac cultivé.

Je vous adore.

Giroselle.

Je vous aime.

Jasmin jonquille.

Je vous aime plus que

moi-même.

Héliolrope.

Je vous offre mon ccur. Véronique.

Je vous vois avec plaisir. Julienne maritime.

La beauté plaît, et les quahtés essentielles attachent.

Pivoine.

Langueur d'amour.

Narcisse jonquille.

L'éducation a développé vos bonnes qualités.

Légéreté.

Poirier.

Les bonnes actions survivent aux siècles. Luzerne arborescente.

Les tresses de vos cheveux sont autant de chaines pour mon cour. Nigelle de Damas.

Liaison dangerense,

Gui commun.

Liens d'amour. •

Cherefeuille. 
Liens.

Lisez dans mon coeur. Longue durée.

Lustre.

Luxe.
Clématite bleue.

Dauphinelle d'Ajax,

Pin.

Renoncule des jardins.

Giroflée des jardins.

Ma faible voix veut célé-

brer vos charmes.

Magnificence.

M'aimez vous.

Majesté.

Ma tendresse est pure.

Méchanceté.

Mélancolie.

Mérite caché,

Merveille.
Vélar des boutiques. Tulipe.

Chrysanthême des prés.

$\boldsymbol{L}$ is blanc.

Ornilhogale pyramidal.

Renoncule scélérate.

Géranium triste, saule pleureur.

Coriandre.

Murier blanc.

Mes regrets vous suivent au tombeau.

Message:

Asphodèle.

Iris de Perse.

M'est-il permis d'espérer le bonheur?

Trèfle.

Mes yeux ne voyent que vous.

Modestie.

Helianthe à grandes fleurs.

Mort.

Mourons ensemble.

Murmures.

Mýstère.

Tiolelte odorante.

Cyprès.

Mrurier noir.

Peuplier.

N'abusez pas des plaisirs. Safran, 
Ne moubliez pas.

Myosotis.

Ornement.

Charme.

Oubli.

Oublions le passé.

Millepertuis.

Paix.

Id.

Parure.

Pensez à moi.

Perfidie.

Olivier.

Mogori.

Violette, pensée.

Laiche.

Persévérance.

Chiendent.

Persuasion.

Guimauve.

Peut-être un jour vous m'apprécierez mieux. Piége.

Piété,

Tussilage odorant.

Gouet gobe-mouche.

Grenadille bleue.

Plaintes.

Peuplier.

Plaisir.

Gesse à larges feuilles.

Plaisir champêtre. Roseau des jartins.

Plaisir délicat.

Gesse odoranle.

Plaisir d'un moment. Ketmie pésiculeuse.

Plaisir toujours nouveau. Hémérocale rouge.

Pleurs.

Hélénie.

Plus je vous vois, plus je vous airne.

Pêcher.

Pourquoi fuir, pourquoi redouter l'amuur?

Niclage belle-de-nuit.

Précaution.

Souci pluviale.

Préférence.

Pommier.

Préjugés.

Noisetier.

Première émotion d'a-

mour.

Lilas, 
Premier regard d'amour. Nivéole printanière. Premier soupir d'amour. $I d$.

Préservatif.

Présomption.

Prodige.

Promptitude.

Prospérité.

Protection.

Protégez-moi.

Prudence.

Pudeur.

Pureté.

Pureté de sentiment.

Quand tu parâ̂s, je suis ivre de volupté.

Raccommodement.

Raillerie.

Rancune.

Rassurez mon ame affligée.

Récompense.

Reconnaissance.

Réfroidissement.

Regrets.

Remords.

Renulez-moi justice.

Réponilez-moi.

Repos.

Respect.
Absinthe citronnelle. Muflier des jardins. Murier blanc.

Giroflée d'été.

Hêtre ou fayard.

Chêne.

Houx commun.

Sorbier domestique.

Acacie pudique.

Iis blano; fleur d'orange.

Verveine.

Rose mousseuse.

Iris de Perse.

Renoncule âcre.

Fumeterre commune.

Verge-d'or。

Chồne.

Figuier.

Viorne boule-de-neige.

Cyprès.

Eipines.

Châlaignier.

Lavande aspic.

Pavot rouge ou coquelicot.

Orme ou ormeall. 
Retour du bonheur. . Muguel de mai.

Réveil.

Béloine.

Rien ne pourra changer

mon cour.

Thuya.

Rigueurs.

Camara.

Rupture.

Sagesse.

Polémoine bleue.

Sauve-garde.

Sauvez-moi.

Séchez ros larmes.

Secret.

Séduction.

Sensations douces.

Acacia, olivier.

Houx commun.

Angélique.

Marjolaine vulgaire.

Muguel angulerux.

Laurier rose.

Sensations heureuses.

Mousses.

Sentiment durable.

Id.

Pin.

Sentiment inaltérable.

Consoude.

Simplicité.

Sincérité.

Girofiée de muraille.

Morelle douce-amere.

Soins maternels.

Solidité.

Chélidoine.

Solitude.

Buis.

Bruyère commune.

Sommeil.

Soupçons.

Pavol somnifére.

Souci des jardins.

Souvenez-yous de moi.

Souvenir ineffaçable.

Mélisse officinale.

Adonide d'été.

Souvenir passager.

Eillet musqué.

Souvenir tendre et douloureux.

Adonide d'été.

Sojez mon apprui.

Tamier. 
Soyons d'accord.

Soyons heureux.

Stuicisme.

Alizier.

MTuguet de mat.

Buis.

Superstition.

Gui de chêne.

Surprise.

Bétoine.

Tendresse réciproque.

Lierre.

Tenez vos promesses.

Prunier.

Timidité.

Violette ociorante.

Toujours.

Immortelles.

Tout amour.

Myrle.

Toute belle.

Amarillis.

Toute bonne.

Sauge.

Tout est soumis à votre empire.

Frêne.

Trahison.

Ciguë.

Tranquillité.

Alysse des rochers.

Triomphe.

Laurier franc.

Tristesse.

If.

Union.

Grenadier.

Unissons•nous,

Epilobe à épi.

Vérité.

Vertu.

Morelle doucearmère.

Vice.

Menthe.

Victoire.

Ivraye.

Palmier.

Virginité.

Fleur d'orange.

Volupté.

Rose mousseluse.

Vos at traits me charment. Liciet cullivé.

Vos bonnes qualités vous font aimer.

Tilleul. 
Vos qualités surpassent
vos charmes.
Réséda odorant.

Vos soins me rendent la vie.

Passe-pelours.

Vos yeux font de cruelles

blessures. Fipérine vulgaire.

Votre aulace m'étonne. Mílèze.

Votre beauté est noble et majestueuse. Rose trémière.

Votre image est tracée dans mon cœur. Fusain.

Votre présence a dissipé le trouble de mon ame. Romarin.

Votre présence adoucit mes peines. Jujubier commun.

Votre vue cause ma joie. Ornilhogale.

Vous avez quoique jeune la prévoyance de l'âge mûr.

$$
\text { Taget. }
$$

Vous brillez de mille attraits.

Renoncule des jardins.

Vous embrâsez mon cœur. Dictame blanc.

Vous êtes aimable. Jasmin blanc.

Vous êtes belle, mais froide.

Hortense.

Vous êtes bienfaisante sans ostentation. Joubarbe des toits:

Vous êtes lans le sentier de la gloire. Parnassie. 
Vous êtes digne de l'immortalité.

Vous êtes jolie.

Cèdre.

Vous êtes ma divinité. Giroselle.

Vous êtes prévoyante. Souci pluviale.

Vous êtes remplie de gràces.

Butome à ombelle.

Vous êtessans prétention. Coquelourde.

Vous êtes un assemblage de perfection.

Quiltet de poëte.

Vous faites mes délices. Fraisier.

Vous faites mon tourment.

Ixia.

Vous inspirez la confiance.

Centaurée musquée-

Vous inspirez l’amour. Cupidone bleze.

Vous inspirez les plus tendres sentimens.

Tubéreuse.

Vous inspirez les sentimens les plus purs. Q'illlet des jardins. Vous m'abandonnez. Scabieuse.

Vous m'abreuvez d'amertume.

Absinthe vulgaire.

Vous m'aimez et vous me donnez la mort. Jacinthe orientale.

Vous m'avez trompé. Siléné attrape-mouche.

Vous m'éclairez.

Bluet des blís.

Vous me consolez de tuutes mes peines. Sureau commun. 
Vous me dédaignez. Salicaire à épis.

Vous me délaissez. Scabiense.

Vous me donnez la mort. Aconit.

Vous me fuyez.

Epinesinelte.

Vous me glacez.

F'icoïde.

Vous m'enchaînez.

Iiseron.

Vous m'enchantez.

Circé.

Vous m'enflammez.

Dictame blanc.

Vous me plaisez.

Groseiller.

Vous me rendez le cou-

rage.

Vous m'inspirez.

Vous n'aimez que vous.

Vous n'êtes que belle.

Vous persuadez mon cœur.

Vous plairez à tout âge. Saule.

Vous possédez des qualités essentielles.

Vous refusez mes soins. Gentiane jaune.

Vous régnez dans mon cœur.

Vous rendez le calme à mon ame.

Vous réunissez tout.

Vous seul occupez ma pensée.

Vousseul pouvez guérir mon cœur.
Basilic.

Bourrache.

Narcisse des poëtes.

Digilale pourprée.

Rosier églantier.

Noyer.

Spirée.

Iupin sarié,

Ananas.

Violelle, pensée:

Origan dictame. 
Vous tardez à faire mon bonheur.

Tulipier:

Vous vous faites attendre. Crysocome linosiris.

FIN.

A CHALON-SUR-SAONE, DE L'IMPRIMERIE DE DEJUSSIEU. 


\section{$E R R A T A$.}

Page 24, ligne I1 : periklëisô, lisez périklêizô.

Page 41, ligne 22: avec la rose tendre, lisez avec le rose tenlre.

Page 64, ligne 20: Olrvier d'Europe. Paix; ajoutez Sagesse.

Page 108, ligne 23: il doit être renflé, lisez ils doivent être renflés. 


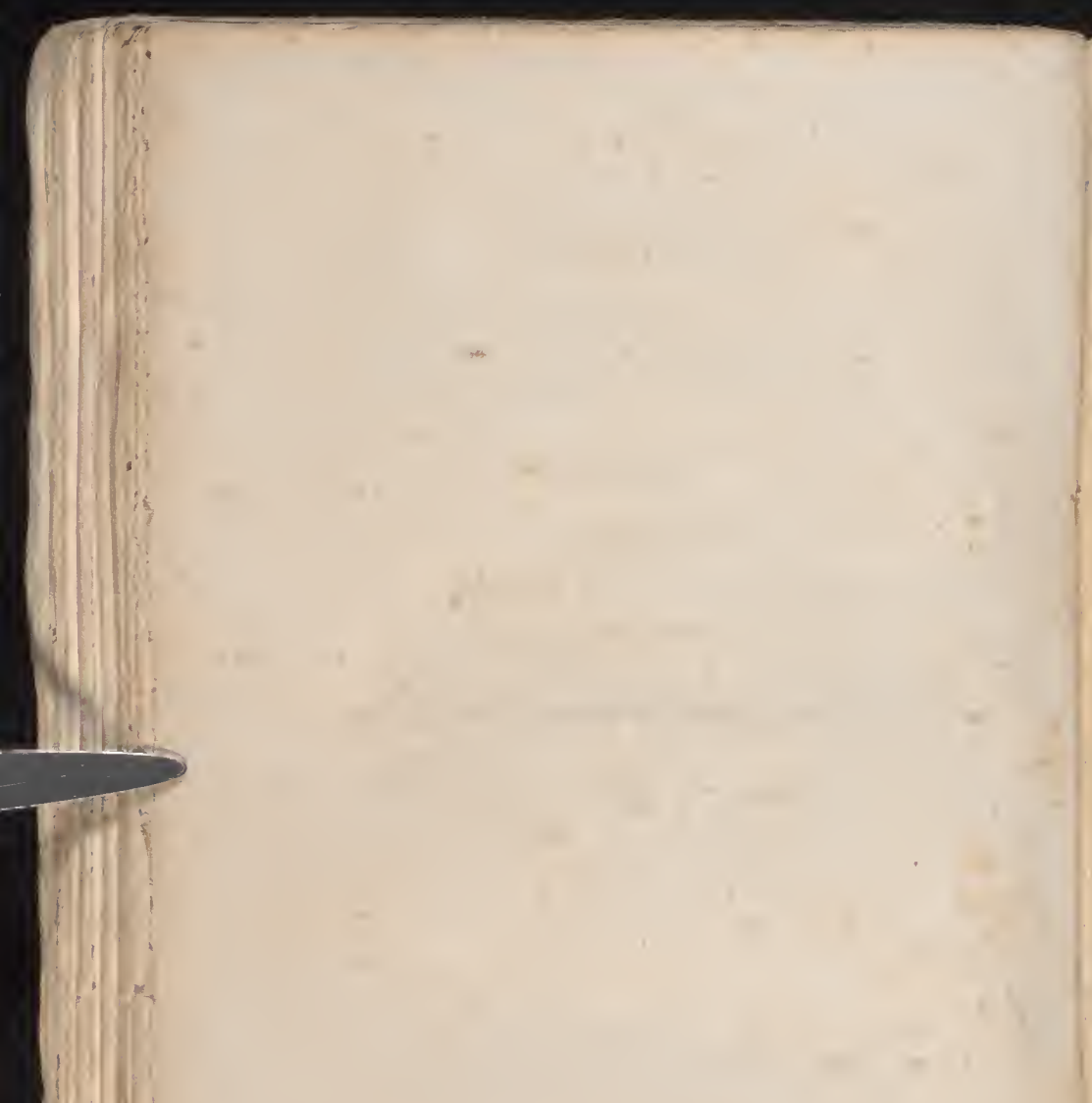




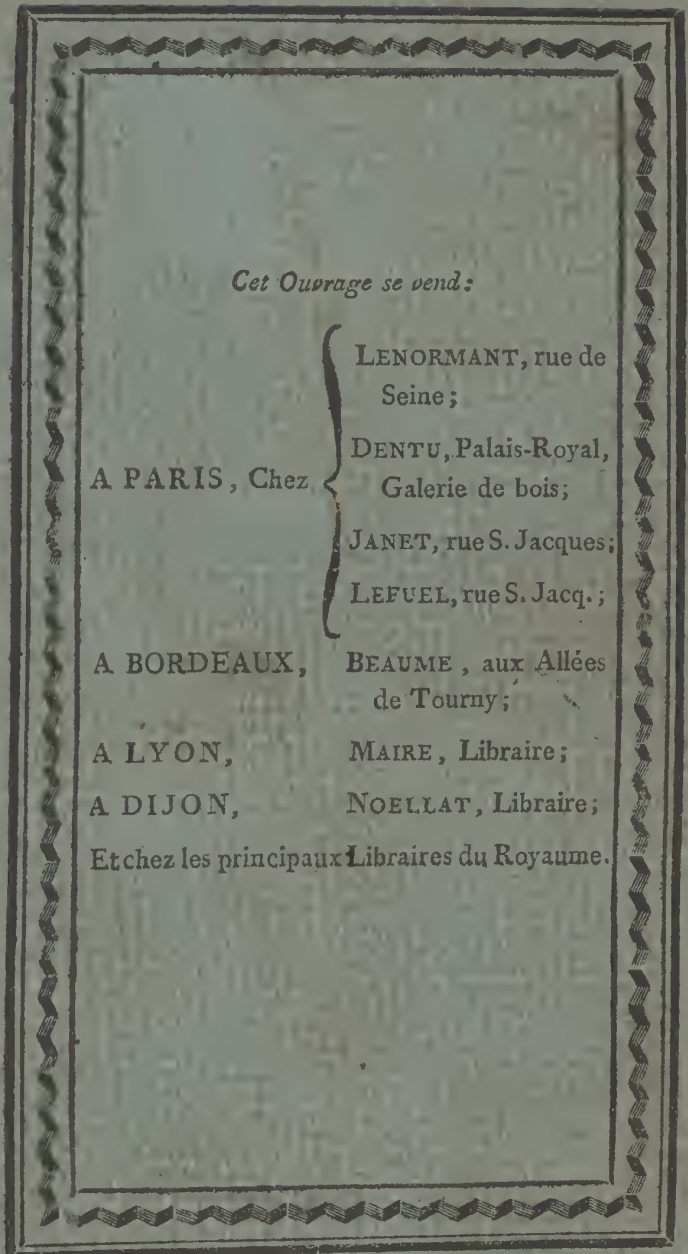

